\title{
Evolution of Poecilimon jonicus group (Orthoptera: Tettigoniidae): a history linked to the Aegean Neogene paleogeography
}

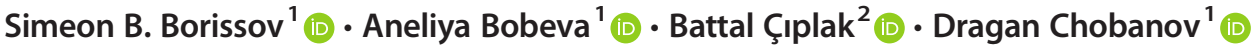

Received: 15 July 2019 / Accepted: 1 October 2020 / Published online: 26 October 2020

(C) The Author(s) 2020

\begin{abstract}
The Aegean archipelago is among the largest on Earth with astonishing biodiversity within Europe. Its territory underwent a massive geotectonic transformation in Neogene that resulted in multitude of changes in land-sea configuration and disintegrated the formerly united Aegean land to a complicated mainland-archipelago system. Therefore, it represents an excellent laboratory for studying evolution of terrestrial fauna. In the present study, we use a model group of flightless bush crickets with annual reproduction cycle-Poecilimon jonicus species group - to trace correlation of lineage diversification with the known paleogeographic events in the Aegean area. The group belongs to the hyperdiverse genus Poecilimon and has a disjunct distribution along the Hellenic arc from southwestern Anatolia through Crete to the western Balkans and the Apennines. To test our hypothesis, we inferred phylogenetic relationships of the $P$. jonicus group sensu lato using a nuclear fragment covering two spacers of the ribosomal cistron (ITS1 + ITS2). To study intra-group phylogeny, we compared mitochondrial phylogenies based on two matrices - (1) a concatenated ND2 and COI dataset of $1656 \mathrm{bp}$ and (2) a 16S rRNA + 12S rRNA dataset of $1835 \mathrm{bp}$. As a second step, we estimated divergence times applying Bayesian approach with BEAST and a relative rate framework with RelTime on the mitochondrial matrices. We compare trees calibrated based on evolutionary rates and tectonic events and discuss radiation scenarios in concordance with known paleogeographic events in the Aegean area. Our results revealed robust phylogeny of the Poecilimon jonicus group and confirmed a strong link between its evolution and the Aegean paleogeography. The phylogenetic relationships of the group supported reconsideration of its systematics.
\end{abstract}

Keywords Phylogeography $\cdot$ Evolution $\cdot$ Orthoptera $\cdot$ Poecilimon $\cdot$ Paleogeography

\section{Introduction}

Archipelagoes provide rich and comparatively simple experimental sets for studying the evolution of terrestrial organisms due to their small size, isolated biotas, and possibilities for a more precise dating of vicariant events in comparison with mainland systems (Shaw and Gillespie 2016). In addition, isolated islands maintain flightless fauna due to a combination

Electronic supplementary material The online version of this article (https://doi.org/10.1007/s13127-020-00466-9) contains supplementary material, which is available to authorized users.

Dragan Chobanov

dchobanov@gmail.com

1 Institute of Biodiversity and Ecosystem Research, Bulgarian Academy of Sciences, 1 Tsar Osvoboditel Boulevard, 1000 Sofia, Bulgaria

2 Department of Biology, Faculty of Science, Akdeniz University, 07058 Antalya, Turkey of factors selecting against unwanted spread and excessive energy and water loss. Vogler and Timmermans (2012) state that "the lack of dispersal may not only result in deeper genetic subdivision, but also in a speed-up of molecular rate of change"; hence, micropterous island populations may be subjected to accelerated diversification. A combination of a diverse group with fast reproduction and low mobility occurring on a diverse archipelago-mainland system, therefore, is an excellent object for phylogeographic studies.

In the Mediterranean, the Aegean represents one of the largest archipelagos on Earth with more than 7500 islands and islets (Triantis and Mylonas 2009), making it especially interesting for phylogeographic studies. The post-Oligocene collision of the African and Arabian tectonic plates with Eurasia led to the disintegration of the formerly united Aegean landmass, consequently forming the current land-sea configuration (Creutzburg 1963; Steininger and Rögl 1984; Dermitzakis 1990). In late Miocene, tectonic events formed basins and grabens, which were filled by the Tortonian transgression of the Mediterranean Sea, resulting in the first formation of the Aegean Sea that established 
a connection with the Euxinian (Pontian) Basin (Meulenkamp 1977; Dermitzakis 1990; Steininger and Rögl 1984; Jolivet et al. 2006; Popov et al. 2004, 2010). This marine barrier was largely interrupted in the Messinian in two phases - first one (ca. $5.8 \mathrm{Ma}$ ago) is characterized with a smaller-scale sea drop, while in the second (5.6 Ma ago), the basin was drastically affected (Popov et al. 2004) by the desiccation of the Mediterranean resulting in an over $1500 \mathrm{~m}$ drop of the sea level (Dermitzakis 1990; Jolivet et al. 2006; Loget et al. 2006). Re-flooding of the Aegean by the beginning of the Pliocene strongly affected the early evolution of terrestrial biota in this area, while later (Plio-Pleistocene) vicariant and dispersal events were ruled by smaller-scale land-sea configuration changes due to climatic or paleogeographic processes, mostly within the areas separated by the three main Aegean basins and the so-called mid-Aegean trench (reviewed by Poulakakis et al. 2014).

Interdisciplinary studies aiming phylogeographic assumptions accumulated a significant amount of data for various animal groups in the Aegean area (Gantenbein and Keightley 2004; Çıplak 2004; Kasapidis et al. 2005; Poulakakis et al. 2005a, 2005b; Douris et al. 2007; Simaiakis and Mylonas 2008; Çıplak et al. 2010; Papadopoulou et al. 2010). The long history of the Aegean archipelago and availability of paleogeographic, palynological, and paleontological data for this area (e.g., reviews by Dermitzakis 1990; Anastasakis et al. 2006) provide reliable calibration points for divergence time estimations and allow calibration with mutation rates and hypothesizing about major speciation events (Lymberakis et al. 2007; Papadopoulou et al. 2010). As a result, the number of phylogeographic studies in the area recently increased significantly (for a review, see Poulakakis et al. 2014).

Recent studies affirmed Orthoptera as a marker group for phylogeographic reconstructions and testing speciation processes (Çıplak 2004; Çıplak et al. 2010; Korkmaz et al. 2014; Allegrucci et al. 2017; Chobanov et al. 2017; Kaya and Çıplak 2017). The vast diversity of tribus Barbitistini (Ensifera, Tettigoniidae) in the Aegean area (with ca. 10 to $20 \%$ of all Orthoptera in the region) indicates the latter as the possible center of origin of Barbitistini. Poecilimon Fischer, 1853 is the largest genus within this tribus with remarkable diversity in the Eastern Mediterranean (La Greca 1999; Çıplak 2004). This genus represents a group of micropterous bush crickets with low mobility and complicated acoustic communication system that has obviously been subjected to a rapid diversification following the set of the Miocene and especially during the Plio-Pleistocene climatic cycles (compare Çıplak 2004; Kaya et al. 2015; Chobanov et al. 2017). The latter has led to a vast variety of closely related lineages, forming groups of poorly distinguishable morphologically, yet behaviorally and ecologically specialized taxa, most of them currently grouped according to morpho-acoustic and/or genetic similarity (e.g., Heller 1984; Ullrich et al. 2010; Chobanov and Heller 2010; Heller et al. 2011).
Our study focuses on a group of sibling bush cricket species with a disjunct distribution between the Apennines, the western and southern Balkans, Crete, and southwestern Anatolia that form a poorly resolved monophyletic clade according to Ullrich et al. (2010 - 11 taxa studied). This group was first arranged under Poecilimon jonicus group based on considerable similarities in morphology and song structure by Heller (1984, 1988, 2004), while later, some of the taxa were transferred to a group of their own, $P$. inflatus group (Kaya et al. 2018). The external appearance of some of the studied taxa is presented in Fig. 1. The following 17 taxa (10 species), which Sevgili et al. (2018) defined as superspecies group, are considered in our study (ranges of species and the subspecies of $P$. jonicus are shown in Fig. 2):

Western and southern Balkans and Apennines, P. jonicus group sensu stricto: (1) P. jonicus superbus (Fischer, 1853), mainland Italy; (2) P. j. jonicus (Fieber, 1853), northwestern Greece, North Macedonia, and Albania, reaching as north as Montenegro; (3) P. j. lobulatus Willemse, 1982, restricted to a small area in western Greece; (4) P. j. tessellatus (Fischer, 1853), the Peloponnesus peninsula; (5) P. werneri Ramme, 1933, a small coastal area in Albania, southwestern edge of the Greek mainland, northwestern Peloponnesus; (6) P. laevissimus (Fischer, 1853), the Peloponnesus and Italy (Sicily), though the latter occurrence was suggested to be a result of human introduction (K.-G. Heller, pers. comm. in Hochkirch et al. 2016); and (7) P. erimanthos Willemse \& Heller, 1992, endemic to the Erymanthos mountain and its surroundings in the Peloponnesus.

Crete, $P$. cretensis Werner, 1903 - endemic to the island of Crete. The species was earlier associated with the $P$. jonicus group (Heller 1988), while a recent study points out morphological similarities with the $P$. inflatus species group, distributed in southwestern Anatolia (Kaya et al. 2018).

Anatolia, Poecilimon inflatus group (as defined by Kaya et al. 2018): (1) Poecilimon inflatus Brunner von Wattenwyl, 1891 with two subspecies-P. inflatus inflatus and $P$. inflatus lyciae Kaya \& Çıplak, 2018has a narrow range in southwestern Anatolia; (2) $P$. martinae Heller 2004 with two subspecies-P. $m$. martinae and P. m. tlos Heller, 2004-occurs in Antalya and Muğla provinces (SW Anatolia); (3) Poecilimon antalyaensis (Karabag, 1975) with three subspecies - P. a. antalyaensis (Karabag, 1975), P. a. myrae Chobanov \& Heller, 2018, and P. a. anemurium Kaya, Chobanov \& Çıplak, 2018 - distributed along the western Mediterranean coast of Anatolia; (4) Poecilimon isopterus Kaya \& Chobanov, 2018, with a small range in Antalya region; and (5) Poecilimon bilgeri Karabag, 1953, extreme southwestern Anatolia. 


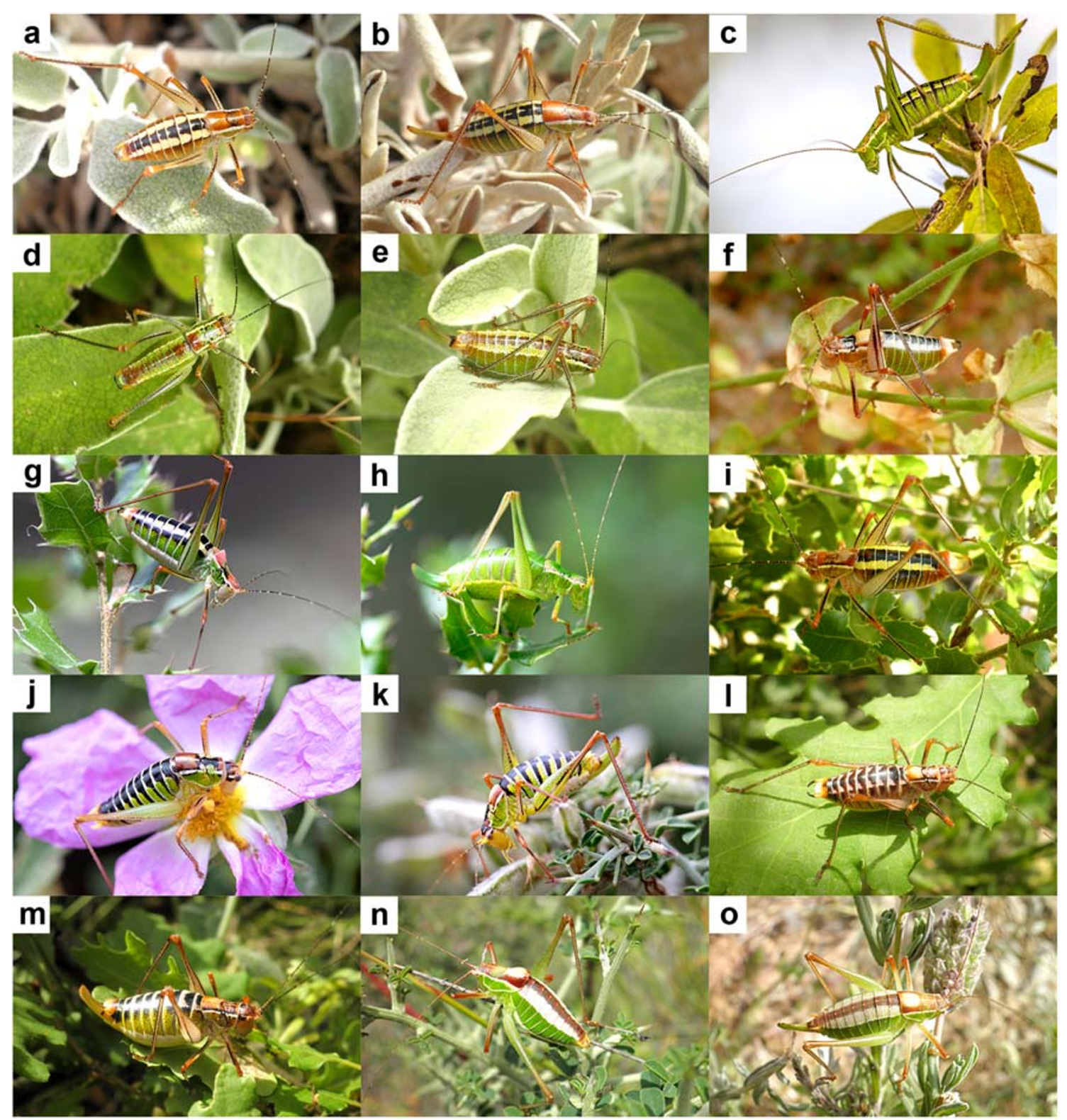

Fig. 1 General appearance of representatives of the Poecilimon jonicus group. a, b $P$. jonicus lobulatus (a male, b female); c $P$. werneri (female); d, e $P$. erimanthos (d male, e female); $\mathbf{f} P$. inflatus lyciae (male); $\mathbf{g}, \mathbf{h}$
P. tessellatus (g male, $\mathbf{h}$ female); i P. laevissimus (male); $\mathbf{j}, \mathbf{k}$ P. cretensis (j male, $\mathbf{k}$ female); I, m P. isopterus (l male, $\mathbf{m}$ female); $\mathbf{n}, \mathbf{o}$ $P$. antalyaensis anemuruim (n male, $\mathbf{o}$ female)
The main objectives of the present study are to, first, reconstruct phylogenetic relationships of $P$. jonicus group sensu lato and consider its systematics in the light of new knowledge and, second, estimate divergence times for the group members and test if radiation steps in their evolutionary history correlate with the known paleogeographic events in the Aegean area. To test these hypotheses, we used sequence data from one nuclear DNA dataset covering two spacers of the ribosomal cistron (ITS1 and ITS2 - internal transcribed spacer 1 and 2, after removing the 5.8S rDNA in-between) and two mitochondrial datasets- ND2 + COI (nicotinamide adenine dinucleotide dehydrogenase subunit 2 and cytochrome $\mathrm{C}$ oxidase subunit I) and 16S rRNA + 12S rRNA (16S rRNA and 12S rRNA fragments after removing the tRNA-Val in-between).

\section{Material and methods}

\section{Sampling and available data}

Sampling for the study was carried by the authors in Greece, Albania, Turkey, and the Republic of North Macedonia between 2014 and 2018. Altogether 12 taxa were sampled, all representing species of the $P$. jonicus and $P$. inflatus groups. 


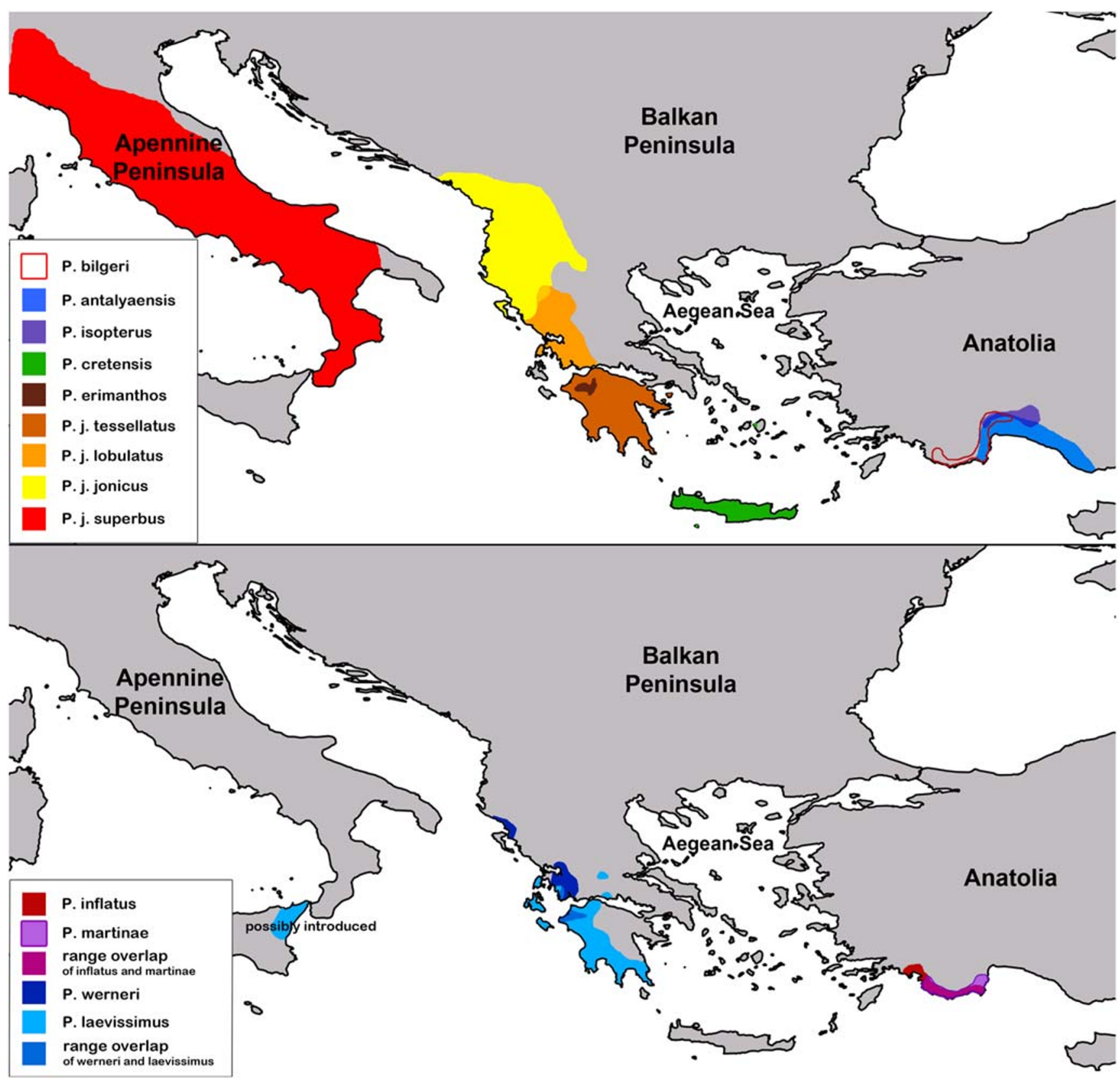

Fig. 2 Distribution of the members of the Poecilimon jonicus group sensu lato-ranges of all species currently considered within the groups $P$. jonicus and $P$. inflatus including subspecies of $P$. jonicus shown with different colors as marked in the plates

Besides, six outgroup taxa were included representing four distinct lineages of Poecilimon and two related genera of Barbitistini-Isophya and Leptophyes. In addition to newly obtained sequences for this study, all available published sequences from the species groups $P$. jonicus and $P$. inflatus, as well as outgroup taxa, best supplementing our samples, were accessed from GenBank (https://www.ncbi.nlm.nih.gov/ genbank/). In order to widen the taxonomic scope of the study, we also used the mitochondrial dataset (16S rRNA - tRNA-Val-12S rRNA fragment) by Ullrich et al. (2010) available from GenBank. Origin of samples, gene fragments studied, and GenBank accession numbers for the downloaded and newly obtained unique haplotypes are shown in Supplementary material A.

\section{DNA extraction and marker amplification}

Total DNA was isolated from hind leg muscle tissue, applying standard protocol for ethanol precipitation. Diluted genomic DNA was used as a template for amplification of two mitochondrial markers - a fragment from the 3' end of the ND2 and COI. For the COI fragment, primers C1-J-2183 - CAACACTT ATTTTGATTCTTTGG (forward) and TL-2-N-3014 TCTAATGCATTAATCTGCCATCTTA (reverse) were used 
with modifications to match orthopterans (Simon et al. 1994). ND2 was amplified with TM-J210 AATTAAGCTAATGG GTTCATACCC (forward) and TW-N1284 AYAGCTTT GAARGYTATTAGTTT (reverse) (Simon et al. 2006). ITS1 and ITS2 together with the 5.8S rDNA gene were amplified with primers TAGAGGAAGTAAAAGTCG (forward) and GCTTAAATTCAGCGG (reverse) resulting in an ITS15.8S-ITS2 fragment (Weekers et al. 2001). The PCR was performed using Supreme NZYTaq II 2x Colourless Master Mix (NZYTech, Lda. - Genes and Enzymes) following the manufacturer's instructions. Temperature cycling was held following Chobanov et al. (2017), with adaptations for hot-start PCR and slight adjustments. For the COI fragment, an initial step at $95{ }^{\circ} \mathrm{C}$ was held for $5 \mathrm{~min}$., followed by 35 cycles, including denaturation $\left(94^{\circ} \mathrm{C}\right.$ for $\left.15 \mathrm{~s}\right)$, annealing $\left(51^{\circ} \mathrm{C}\right.$ for $\left.20 \mathrm{~s}\right)$, and elongation $\left(70{ }^{\circ} \mathrm{C}\right.$ for $90 \mathrm{~s}$ ). Final elongation step was performed at $72{ }^{\circ} \mathrm{C}$ for $15 \mathrm{~min}$. ND2 was amplified with initial step at $95^{\circ} \mathrm{C}$ for 5 min, followed by 35 cycles of denaturation $\left(95{ }^{\circ} \mathrm{C}\right.$ for $50 \mathrm{~s}$ ), annealing $\left(51^{\circ} \mathrm{C}\right.$ for $\left.40 \mathrm{~s}\right)$, and elongation $\left(72^{\circ} \mathrm{C}\right.$ for $\left.80 \mathrm{~s}\right)$, with a final elongation step at $72{ }^{\circ} \mathrm{C}$ for $15 \mathrm{~min}$. For the ITS fragment, the protocol by Ullrich et al. (2010) was applied. Presence of amplification products with certain length was confirmed electrophoretically after $1 \mathrm{~h}$ at $80 \mathrm{~V}$ in $2 \%$ agarose gel containing GelRed $^{\text {TM }}$ gel stain (Biotium, Inc., Hayward, CA, USA). Standard sequencing reaction was performed from both 5' and 3 ' ends with the corresponding primers by Macrogen Europe (Macrogen, Inc., Amsterdam, Netherlands).

\section{Sequence preparation and phylogenetic analyses}

Obtained sequences were trimmed, assembled, and visually checked using CodonCode Aligner version 8.0.2 (CodonCode, Dedham, MA, USA). Sequence alignments were performed in MEGA X (Kumar et al. 2018). Unique haplotypes were determined using DnaSP ver. 5.10 (Librado and Rozas 2009). For the protein-coding sequences, alignments were checked for stop codons to avoid numts.

Due to differences in the length of sequences and/or position of primers, we were not able to use all available from GenBank COI sequences, while ND2 sequences of Poecilimon are mostly missing. Therefore, to reflect full taxonomic composition as used in the ITS phylogeny, we prepared additional mitochondrial matrix from available $16 \mathrm{~S}$ rRNA - tRNA-Val-12S rRNA sequences (Ullrich et al. 2010).

Sequences of the 16S rRNA - tRNA-Val-12S rRNA fragment by Ullrich et al. (2010) available from GenBank were edited by removing the tRNA, and a final matrix of the $16 \mathrm{~S}$ rRNA and 12S rRNA was prepared. The 5.8S rDNA fragment of the ITS1 - 5.8S - ITS2 alignments was removed, resulting in a ITS1 + ITS2 matrix, further in the text referred to as ITS. Own ND2 and COI sequences complemented with corresponding available published DNA fragments were concatenated in a $\mathrm{ND} 2+\mathrm{COI}$ matrix. As a result, three matrices-ITS, COI +
$\mathrm{ND} 2$, and $16 \mathrm{~S}$ rRNA + 12S rRNA - were obtained. The matrices of protein-coding genes were checked for saturation, and alignments were divided by codon position (1st, 2nd, 3rd) using DAMBE 7.0.39 (Xia et al. 2003; Xia 2018). Substitution models for all codon positions of each molecular marker were estimated with jModelTest v. 2.1.7 (Darriba et al. 2012) and PartitionFinder ver. 2.1.1 (Lanfear et al. 2016). Best models were selected under the corrected Akaike information criterion (AICc). Estimated parameters and respective substitution models were implemented in subsequent phylogenetic analyses.

Maximum likelihood (ML) analyses were conducted using RAxML (Stamatakis 2006) on the T-rex online platform (http:// www.trex.uqam.ca/index.php?action=raxml\&project=trex) (Boc et al. 2012). Support of nodes was acquired with 1000 bootstrap resampling. Bayesian inference (BI) analyses were accomplished in Mr. Bayes version 3.2.5 (Ronquist and Huelsenbeck 2003; Ronquist et al. 2005) with four simulations of Markov chains and $4 \times 10^{6}$ generations sampling each 100th tree. Stationary distribution of the MCMC parameters was checked with Tracer ver. 1.7.1 (Rambaut et al. 2018). The first $25 \%$ of trees were excluded as burnin. Results were visualized in FigTree 1.4.3 (http://tree.bio.ed.ac.uk/software/figtree/).

\section{Estimation of divergence times}

Prior to time estimation analyses in BEAST, we performed a maximum likelihood clock test in MEGA X applied to the mitochondrial matrices. The null hypothesis of an equal evolutionary rate was rejected at a $5 \%$ significance level $(P<0.05)$. Thus, for time estimation analyses, we applied uncorrelated lognormal relaxed clock (Drummond et al. 2006). Priors on tree topology were set as obtained from ML and BI trees produced from respective datasets, and taxa for which monophyly was strongly supported (above 90\%) were marked as monophyletic.

To estimate divergence times for the ND2 + COI phylogeny, we followed two calibration strategies. First, we calibrated the BEAST analysis using a substitution rate of 0.0177 site/ Ma for COI, estimated for Aegean tenebrionid beetles and calculated by the age of the mid-Aegean trench (Papadopoulou et al. 2010), which has already been used for bush crickets (Chobanov et al. 2017). Two separate partitions - COI and ND2-were analyzed "unlinked," and the COI substitution rate was set as a prior, while the substitution rate for ND2 was estimated as "linked." Second, in order to reduce possible bias caused by substitution rate variations between lineages, we applied neutral geotectonic calibration on an internal branch of our phylogenies. The welldocumented dating of the separations of Crete from the mainland (1) in Tortonian (10.6 Ma ago; Dermitzakis and Papanikolaou 1981; Dermitzakis 1990) and (2) at the end of Messinian (5.6-5.2; Meulenkamp 1985; Dermitzakis 1990; Anastasakis et al. 2006; Loget et al. 2006) were used as two alternative hypothetical calibration points as they were 
thought to provide efficient calibration assuming that lineages of terrestrial animals were fully isolated on the island (Beerli et al. 1996; Lymberakis et al. 2007). Therefore, we conducted BEAST analyses for the ND2 + COI dataset setting the divergence of $P$. cretensis to $5.6 \pm 0.4$ and at $10.6 \pm 0.4 \mathrm{Ma}$.

BEAST analyses were run using a Yule speciation process and MCMC chain for $100 \times 10^{6}$ generations sampling every 1 $\times 10^{3}$ generations in BEAST 2.5.2 (Bouckaert et al. 2019). BEAST was run on the CIPRES Science Gateway webserver (Miller et al. 2010). Convergence to stationary and the effective sample size of model parameters were checked via Tracer ver. 1.7.1 (Rambaut et al. 2018). Maximum clade credibility trees were established with TreeAnnotator (Rambaut and Drummond 2002-2019) to summarize the BEAST output, discarding the initial $10 \%$ of the trees as burn-in.

Alternatively, the RelTime method, implemented in Mega $\mathrm{X}$, was applied on the ND2 + COI dataset to infer a timetree (Tamura et al. 2012, 2018). Tree topology was set according to our $\mathrm{BI}$ and ML results. One constraint at the branching off of $P$. cretensis was set within the range between 5.2 and 6.0 $\mathrm{Ma}$, and alternatively between 10.2 and $11.0 \mathrm{Ma}$. The Tamura-Nei (Tamura and Nei 1993) substitution model with 5 gamma evolutionary categories was applied.

Molecular clock calibration for the 16S rRNA + 12S rRNA phylogeny using substitution rates would be dubious at this stage. On the other hand, dating the split of $P$. cretensis would have been irrelevant due to unresolved branching (see Results). Therefore, we calibrated the tree according to the results from the paleo-geotectonic dating of the ND2 + COI tree for a highly supported in both phylogenies branch, basal for the studied group.

\section{Bioacoustics}

Male acoustic signals and partly female responses are described in detail for the studied taxa (e.g., Heller 1984; Kaya et al. 2018). To exemplify specific male calling songs, we used our own recordings, performed using Pettersson D500 external microphone connected to ZOOM H2 $(96 \mathrm{kHz}, 24-b i t$ sampling frequency) or Tascam DR-680MKII $(192 \mathrm{kHz}, 24-$ bit sampling frequency) digital recorders and visualized with Audacity 2.1.2. (https://www.audacityteam.org/). Own data were compared with recordings available from OSF online (Cigliano et al. 2020) and Fauna d'Italia (Massa et al. 2012). Details are given in Fig. 9.

\section{Results}

\section{Data characteristics and genetic distances}

The ITS dataset combined from own and published sequences consisted of 665 bp with gaps (630 bp without gaps), including 214 variable and 122 parsimony informative sites, and involved 16 ingroup and 6 outroup taxa (respectively 28 ingroup and 11 outroup haplotypes). The ITS dataset from Ullrich et al. (2010), involving all $P$. jonicus taxa sensu lato and same outgroup taxa (except for the available taxa from Leptophyes and Isophya), included 12 ingroup and 6 outgroup taxa (16 ingroup and 10 outgroup haplotypes). The latter consisted of $717 \mathrm{bp}$ with gaps (679 bp without gaps), including 212 variable and 112 parsimony informative sites. The aligned concatenated mt-dataset of ND2 + COI contained $1656 \mathrm{bp}$ and involved 25 unique haplotypes from 11 ingroup and six outgroup taxa. Included COI fragment had a length of 705 bp with 268 variable and 237 parsimony informative sites, and the ND2 fragment had 951 bp with 548 variable and 443 parsimony informative sites. The $16 \mathrm{~S}$ rRNA $+12 \mathrm{~S}$ rRNA dataset had a final length of $1835 \mathrm{bp}$, involved 25 unique haplotypes from 11 ingroup and six outgroup taxa, and included 72 indels, 666 variable sites, and 506 parsimony informative sites. No numt signs were detected in alignments of protein-coding sequences. Saturation tests applied did not show signs of significant saturation. Best substitution models for each matrix and for codon positions of the protein-coding genes are given in Supplementary material B.

\section{Phylogenetic inferences}

The BI trees obtained from the combined (Fig. 3a) and published (Fig. 3b; Ullrich et al. 2010) ITS matrices well supported the monophyly of the group including the Balkan, Cretan, and Anatolian lineages, except for Poecilimon bilgeri that grouped with P. pergamicus Brunner von Wattenwyl, 1891, positioned closer to the basal branch of Poecilimon. The support for the monophyly of the group rose when lowering the sample size (Fig. 3b), though one haplotype described as $P$. $j$. jonicus 031 grouped with $P$. brunneri (Frivaldzsky, 1868) and $P$. zwicki Ramme, 1939. The ML analysis provided the same topology; yet, with poor support for some branches, therefore it is not shown here. The analyses failed to resolve the ingroup relationships, grouping only sequences from the same taxa, including subspecies.

The ML and BI analyses of the ND2 + COI matrix supported the group monophyly while also providing good resolution and very high support for most branches not only at a group level but also within groups (Fig. 4a). P. bilgeri, $P$. martinae, and $P$. jonicus superbus were missing from the analyses due to a lack of or very short sequences available. The ML and BI trees of the concatenated matrix placed Isophya + Leptophyes as a sister clade to Poecilimon. Within Poecilimon, the outgroup taxa formed a sister group to $P$. jonicus sensu lato, as follows: P. hamatus Brunner von Wattenwyl, $1878+(P$. pergamicus $+(P$. zwicki + P. brunneri)). 
Fig. 3 Phylogenetic relationships of the members of the Poecilimon jonicus group sensu lato with four outgroups from the genus Poecilimon and two outgroups from additional genera of Barbitistini ( $P$, Poecilimon; L., Leptophyes; I., Isophya) based on Bayesian inference analysis of ITS1+ITS2 sequences. a 665 bp alignment-tree of sequences obtained in this study and from GenBank (Ullrich et al. 2010) and b 717 bp alignment-tree of sequences available from Ullrich et al. (2010). Node support is shown at (below) resolved branches

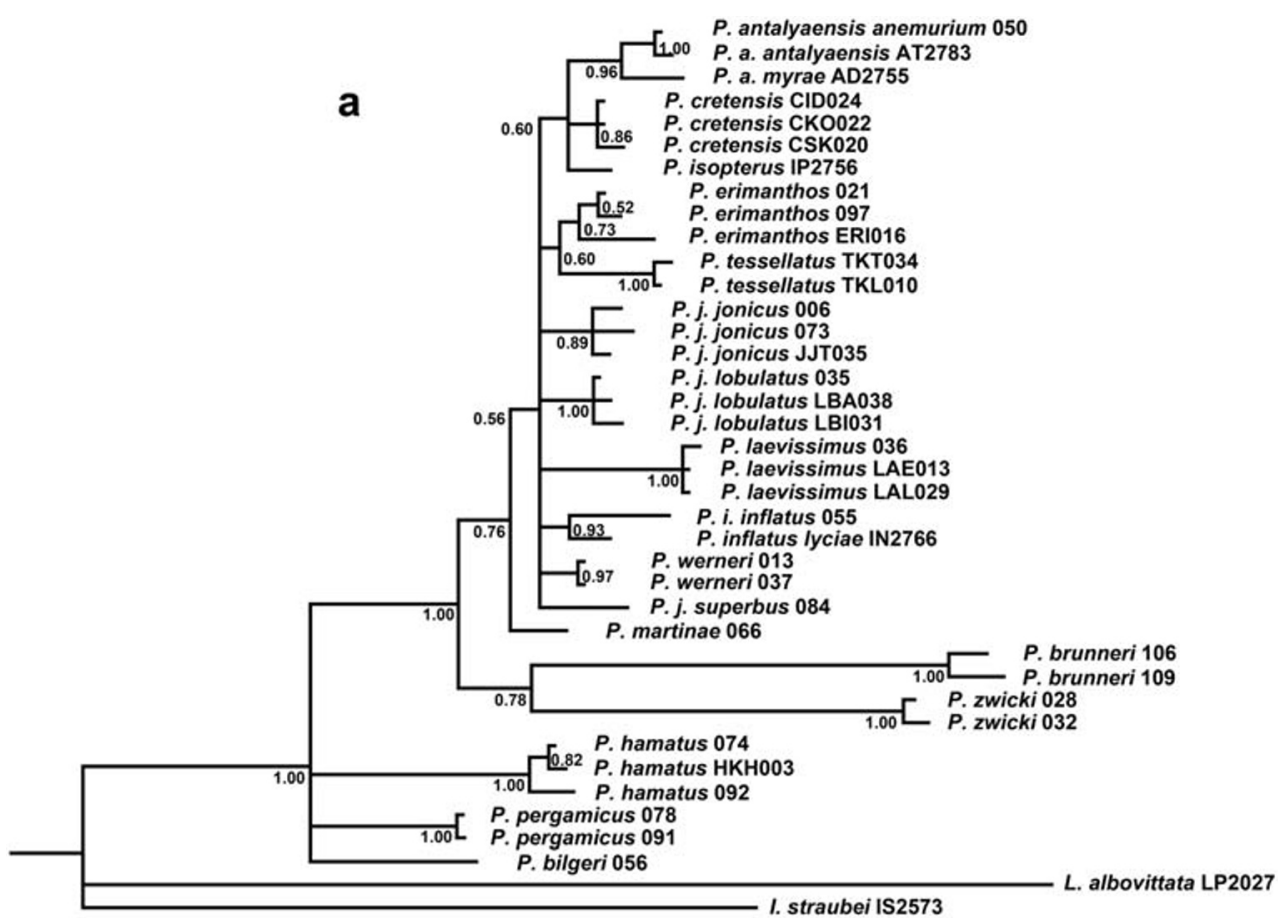

The ML tree based on the $16 \mathrm{~S}$ rRNA + 12S rRNA dataset did not show good resolution and support (tree not shown). BI tree generally agrees with the published maximum parsimony tree (Ullrich et al. 2010) (Fig. 4b). P. bilgeri groups with $P$. pergamicus within the branch $[(P$. pergamicus + $P$. bilgeri $)+(P$. zwicki $+P$. brunneri $)]$, sister to $P$. hamatus $+P$. jonicus group s.l., while the monophyly of $P$. jonicus group is fully supported. Anatolian $P$. antalyaensis (its sister taxon, $P$. isopterus, was not presented in the dataset) branches out first. Support for the following grouping was poor, except for the well-outlined groups of $P$. inflatus $+P$. martinae, $P$. erimanthos $+(P$. jonicus tessellatus $+P$. laevissimus $)$, and $P$. werneri $+(P . j$. superbus $+P . j$. jonicus $)$. The latter groups reflect the terminal grouping in the ND2 + COI tree.
Phylo-spatial dimension of the $P$. jonicus group based on combined data from the phylogenetic trees is summarized in Fig. 5 (mostly based on Fig. 4a; for relative branch lengths and branch support compare with Fig. $4 \mathrm{a}$ and b). The Anatolian taxa $P$. antalyaensis and $P$. isopterus form a clade that branches off first within $P$. jonicus group. The Cretan lineage (P. cretensis) branches off next (Fig. 4a) or belong to the poorly resolved crown clade (Fig. 4b). Based on the ND2 + COI phylogeny, the crown clade is formed by the Balkan lineages together with the Anatolian $P$. inflatus. Within the crown clade, two Balkan lineages may be outlined as follows. The Northern Balkan clade consists of P. werneri $+(P . j$. superbus $+(P . j \cdot$ jonicus $+P . j$. lobulatus $))$. The Southern Balkan clade includes the taxa occurring on the 
Fig. 4 Phylogenetic relationships of the members of the Poecilimon jonicus group sensu lato with four outgroups from the genus Poecilimon and two outgroups from additional genera $(P$, Poecilimon; L., Leptophyes; I., Isophya). a Combined maximum likelihood and Bayesian inference phylogenetic trees based on a 1659 bp alignment of the $\mathrm{COI}+$ ND2 mitochondrial dataset and $\mathbf{b}$ Bayesian inference phylogenetic tree based on a $1835 \mathrm{bp}$ alignment of the 16S rRNA+12S rRNA mitochondrial dataset (Ullrich et al. 2010). Node values at branches show node support: above, ML bootstrap proportions; below, BI posterior probabilities; asterisk $(*)$ indicates branches resolved by one of the analyses

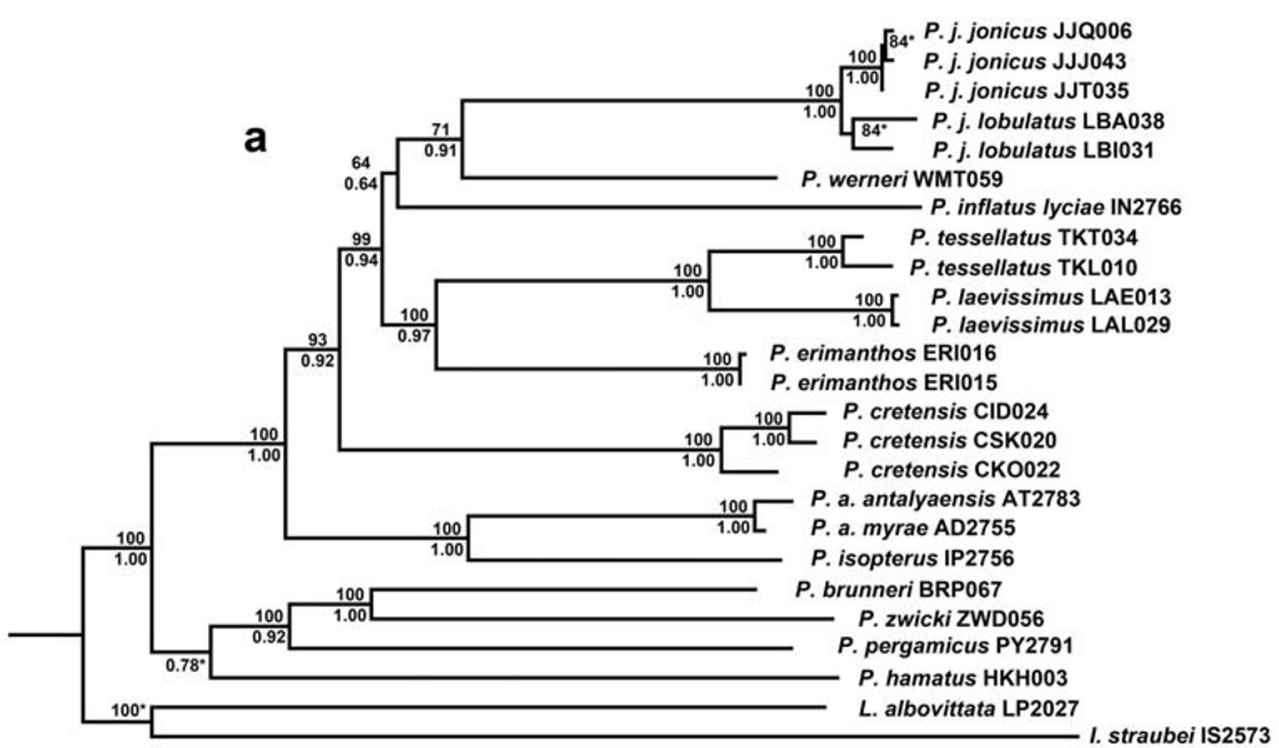

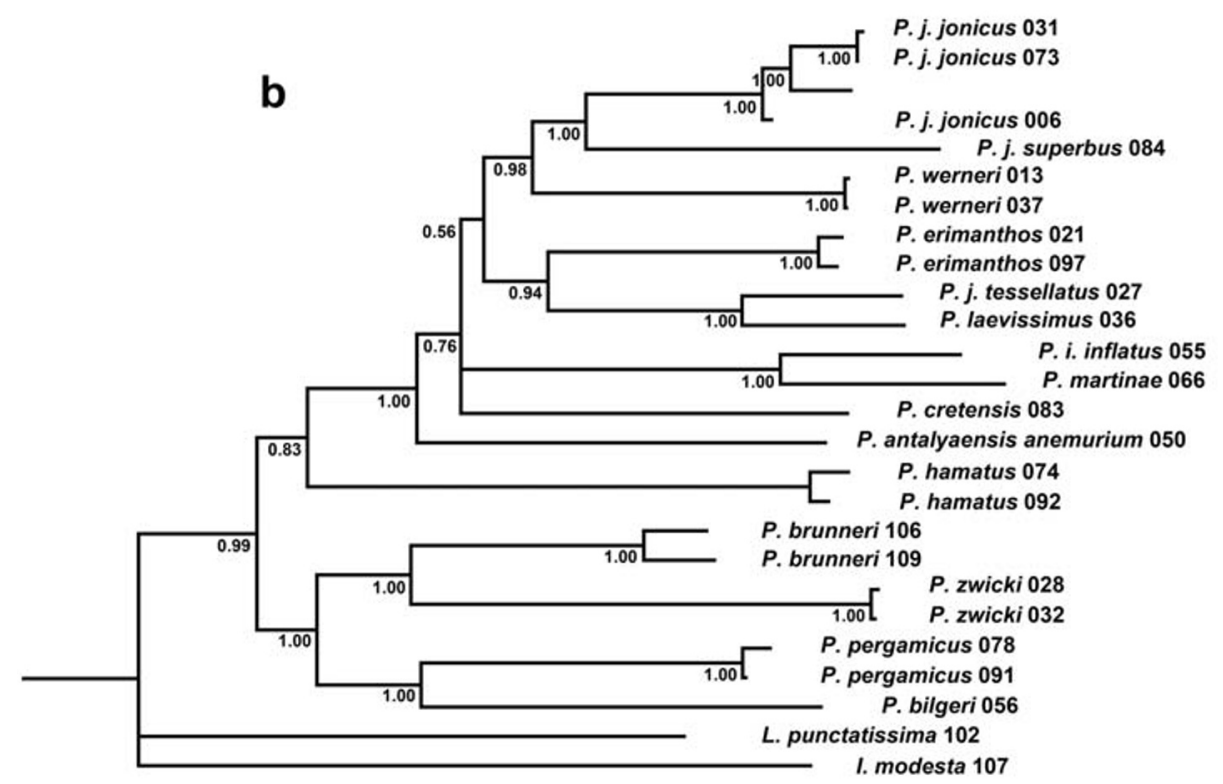

Peloponnesus Peninsula, namely, $P$. erimanthos $+(P$.jonicus tessellatus $+P$. laevissimus). The third group in the crown clade consists of the Anatolian taxa $P$. inflatus and $P$. martinae, whose relationships with either of the Balkan clades remain uncertain.

\section{Estimation of divergence times}

The BEAST chronograms of the "unlinked" datasets of COI and ND2 calibrated by 0.0177 substitution/site/Ma (Fig. 6a) suggested that $P$. jonicus group sensu lato shares the last common ancestor 7.90/7.35 (COI/ND2) Ma ago. The TMRCAs for the internal clades in $P$. jonicus group sensu lato by the same chronograms (COI/ND2) are as follows: (i) 5.57/4.00 Ma for P. antalyaensis $+P$. isopterus, (ii) 7.33/6.66 Ma for Cretan +
Balkan clades, (iii) 5.89/* Ma (COI) for P. inflatus + all Balkan species (COI chronogram only), (iv) 6.63/4.47 Ma for the three taxa in Peloponnesus, (v) */6.13 Ma for P. inflatus + (P. werneri $+P$. jonicus s.str.) clade (ND2 chronogram only), and (vi) 4.96/5.11 Ma for P. werneri $+P$. jonicus (except $P$. $j$. tessellatus). The chronograms of $\mathrm{COI} / \mathrm{ND} 2$ estimated the TMRCA of Barbitistini as 10.89/11.19 and that of the members of Poecilimon as 9.55/9.63 Ma.

The BEAST chronogram and RelTime timetree of the ND2+ COI calibrated by the separation of Crete in Tortonian as $10.6 \mathrm{Ma}$ produced significantly extreme TMRCAs contradicting the rest of our results and published analyses for Poecilimon and Isophya (compare Chobanov et al. 2017; for additional comments see Discussion); thus, we do not consider them and those are not shown here. The second chronogram of ND2 + COI, calibrated 


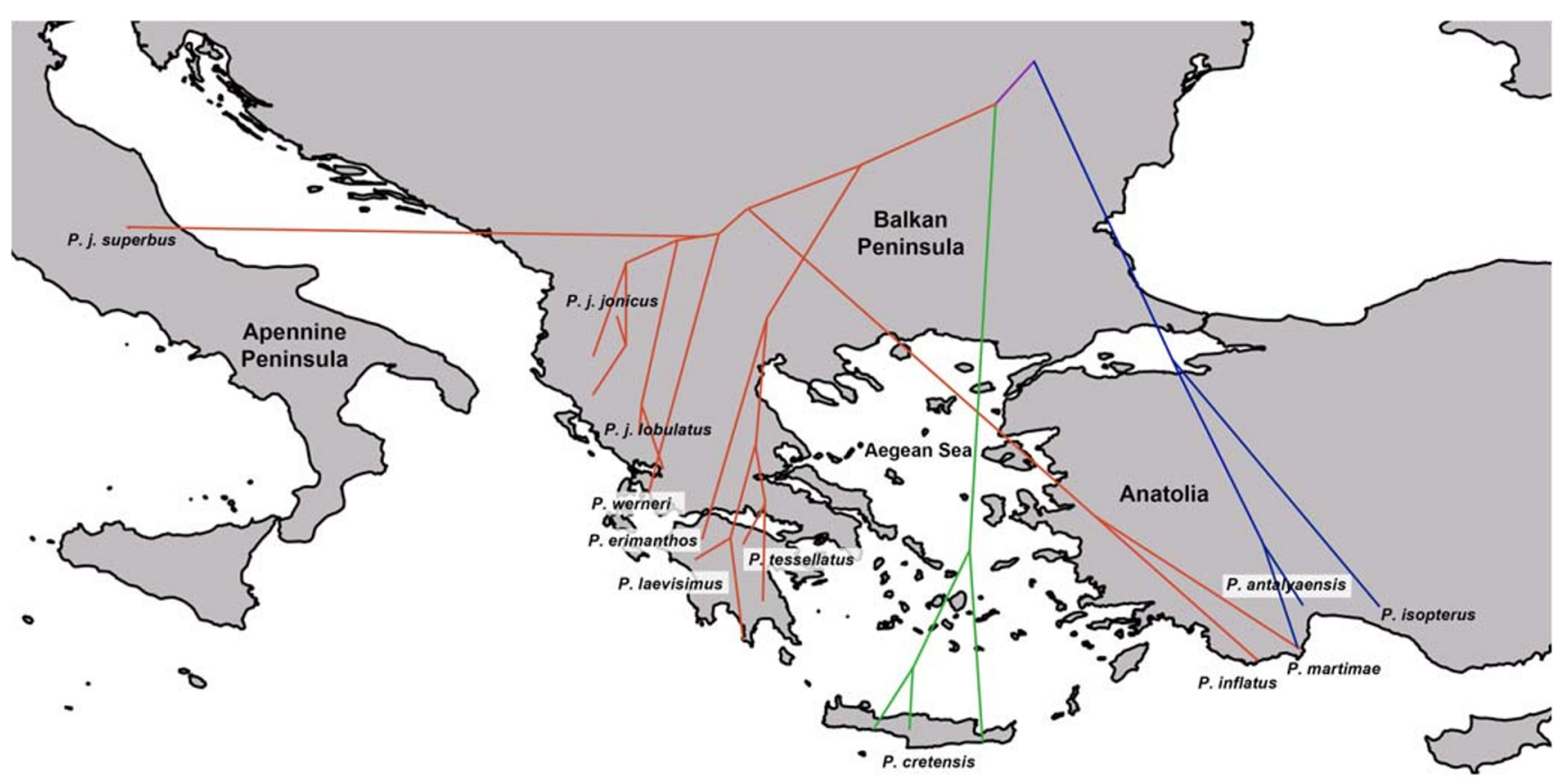

Fig. 5 Phylo-spatial dimension of the $P$. jonicus group based on the mtDNA phylogeny (data combined from COI+ND2 and 16S rRNA+12S rRNA datasets). Blue, "Anatolian" lineage; green, "Cretan" lineage; orange, "Balkan" lineage including Poecilimon inflatus

by separation of the Cretan lineage ca. 6-5.2 Ma ago, produced ancestral times largely congruent with the RelTime chronogram and rate calibrated analyses. The BEAST and RelTime (RTC) chronograms for ND2 + COI calibrated by the Cretan lineage split as $5.6 \pm 0.4 \mathrm{Ma}$ agreed well in node ages (combined results are shown in Fig. 6b). The TMRCAs (BEAST/RTC) are as follow: (i) Barbitistini 10.24/* Ma, (ii) Leptophyes + Poecilimon 9.12/*, (iii) Poecilimon clade 7.81/7.79 Ma, (iv) P. jonicus group sensu lato $6.05 / 6.13 \mathrm{Ma}$, (v) P. antalyaensis + P. isopterus 3.52/3.78 Ma, (vi) Cretan + Balkan clades 5.57/ $5.60 \mathrm{Ma}$ (calibration node), (vii) Anatolian P. inflatus + mainland Balkan species 5.20/5.11 Ma, (viii) P. inflatus + (P. werneri + $P$. jonicus) clade $4.93 / 4.91 \mathrm{Ma}$, (ix) the clade including three species in Peloponnesus 4.44/4.47 Ma, and (x) P. werneri + P. jonicus 4.3/4.26 Ma, (xi) P. laevissimus $+P$. tessellatus ca. 1.73/1.71 Ma. Times to terminal nodes corresponding to intraspecific lineage splits were dated later than 0.9 Ma.

On the 16S rRNA + 12S rRNA tree BEAST calculated the TMRCAs of nodes as follow (Fig. 6c): (i) Barbitistini 9.34 Ma, (ii) Poecilimon clade $7.91 \mathrm{Ma}$, (iii) P. jonicus group sensu lato (calibration node) $6.24 \mathrm{Ma}$, (iv) $P$. jonicus group after the split of P. antalyaensis $5.81 \mathrm{Ma}$, (v) Anatolian P. inflatus + P. martinae + Cretan + Balkan species $5.81 \mathrm{Ma}$, (vi) $P$. cretensis $+(P$. inflatus $+P$. martinae) $5.27 \mathrm{Ma}$, (vii) the Balkan clade 5.30 Ma, (viii) the Southern Balkan clade 4.35 $\mathrm{Ma}$, (ix) the northern Balkan clade $4.58 \mathrm{Ma}$, (x) the divergence of Italian P. jonicus superbus $3.87 \mathrm{Ma}$, (xi) P. inflatus + P. martinae $2.39 \mathrm{Ma}$, and (xii) P. laevissimus + $P$. tessellatus $2.06 \mathrm{Ma}$. Times to terminal nodes corresponding to intraspecific lineage splits were dated later than $0.97 \mathrm{Ma}$.

\section{Discussion}

Results of the present phylogenetic and time estimation analyses can be evaluated from different aspects such as the evolution of Barbitistini, Poecilimon, and P. jonicus and $P$. inflatus groups. In the analyses, the number of taxa from Barbitistini and Poecilimon is limited; yet, support to monophyly of the genus is the first implication to be mentioned (Ullrich et al. 2010; Chobanov et al. 2017). In addition, present data offer significant clarification about the evolutionary history of the lineages concerned and some implications concerning the paleogeographic history of the Aegean area.

Five out of seven time estimation analyses produced largely agreeing ages for the resulting chronograms. The BEAST chronograms of COI and ND2 datasets calibrated by the substitution rate of the COI (Papadopoulou et al. 2010), the RelTime chronogram of COI+ND2, and the BEAST chronograms of COI+ ND2 and 16S rRNA+12S rRNA, calibrated by the separation of Crete in post-Messinian period, resulted in very similar TMRCAs for almost all nodes (Fig. 6a, b, c). Small, though, for basal nodes, significant differences were observed between analyses calibrated for substitution rate versus those calibrated for paleogeographic events. Yet, these differences largely overlap if consider 95\% HPD intervals (Supplementary material C). This is not unexpected as the rate of evolution may vary depending on lineage, time, and geography (Brower 1994; Shapiro et al. 2006; Percy et al. 2004; Papadopoulou et al. 2010; Kaya and Çiplak 2016). Received TMRCAs allow us to make robust statements about the age of the ancestor, the place of origin, and the historical factors which triggered the evolution of Barbitistini. 
Fig. 6 Timetrees for the $P$. jonicus group based on different phylogenies and time calibrations with node labels referring to the time estimation in millions of years. a BEAST maximum clade credibility tree inferred from COI and ND2 partitions calibrated for the substitution rate of COI; $\mathbf{b}$ BEAST chronogram and RelTime timetree inferred from the $\mathrm{COI}+\mathrm{ND} 2$ phylogeny calibrated for the last separation of Crete (values above nodes, BEAST chronogram estimations; values below nodes, RelTime timetree estimations); c BEAST chronogram inferred from the $16 \mathrm{~S}$ rRNA+12S rRNA phylogeny calibrated for the TMRCA (interval) of $P$. jonicus group (node 12) as suggested from the COI+ND2 chronogram. Different topologies of the trees are marked with "**" for the COI partitions and “**" for the ND2 partition on (a) and different topology of the BEAST and RelTime trees on (b). Numbers in white circles correspond to data in Supplementary material C. Light blue vertical band marks the onset of the northern hemisphere glaciation and dark blue lines mark major climatic switches in the

Pleistocene. Uniform gray areas below the trees show united Aegean landmass (left) and reunification of large areas in Messinian (right), while striped areas show disintegrated state of the Aegean

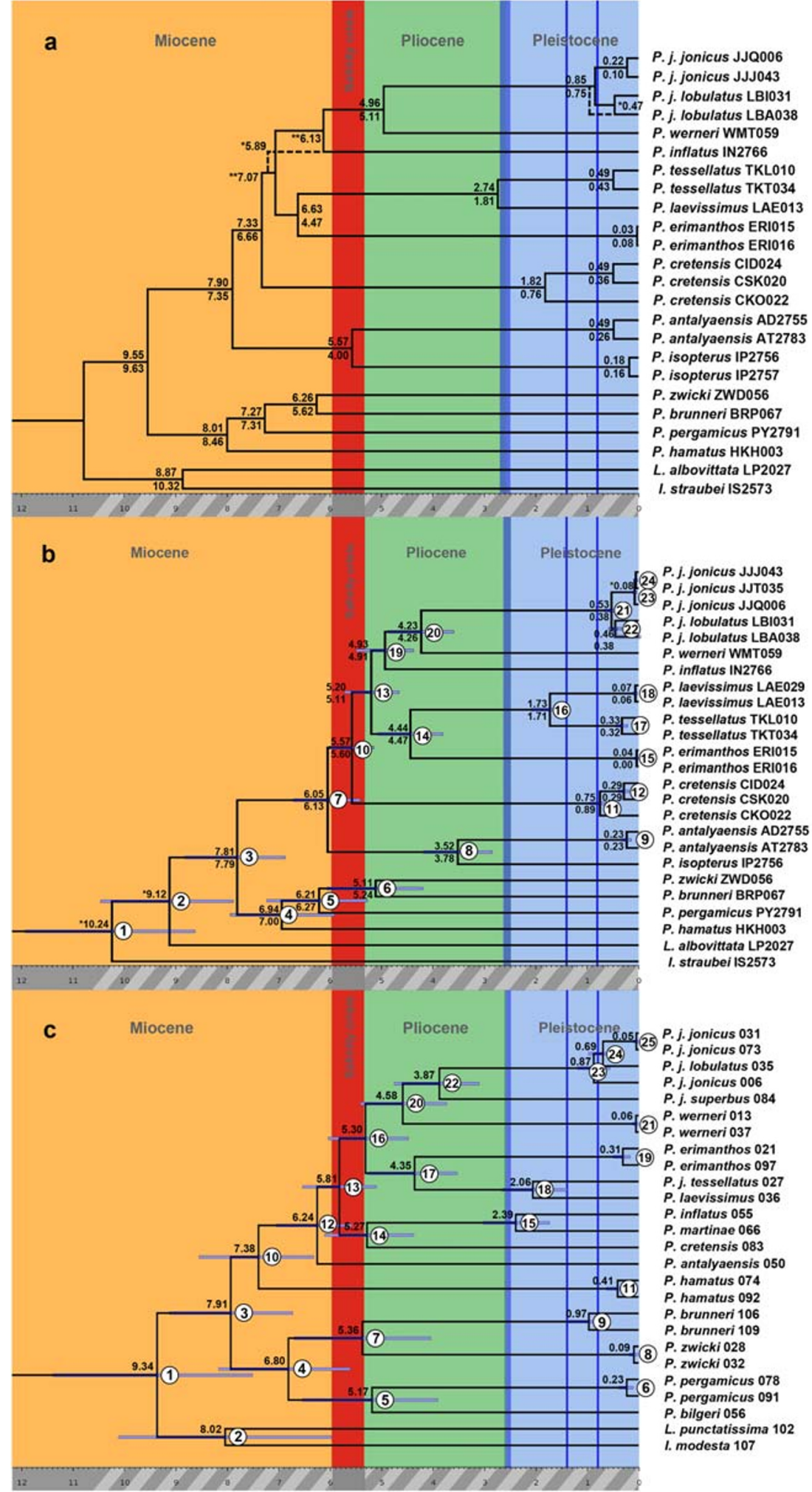

Members of Poecilimon - the most speciose genus of the tribus - shared last common ancestor ca. 9.6-7.8 Ma, a period well corresponding to the first transgression of the Aegean area in Tortonian. Similarly, the last common ancestor of Isophya, the second largest lineage in the tribus, was dated at 8.3-8.8 Ma (Chobanov et al. 2017), again corresponding to the same geotectonic event. The split of Poecilimon from Isophya + Leptophyes was dated ca. 14-12 Ma (Chobanov et al. unpublished data), a time prior to Tortonian that well corresponds to current time estimations. Thus, we conclude 
that Barbitistini radiated from a common ancestor in Serravallian/Langhian and the marine transgression of the Aegean area in Tortonian (Fig. 7b) is the main event that triggered early lineage divergence. At present, members of the tribus are mainly ranged in derivatives of the old Aegean Plate. The latter inferences support Çıplak (2004) in his assumption that the tribus radiated from an Aegean lineage in Langhian when the Aegean land represented united subcontinent in the Tethys Sea (Fig. 7a). The transgression of the Aegean as an evolution driving factor has been observed in several other lineages (Douris et al. 2007; Çılak et al. 2010; Papadopoulou et al. 2010; Parmakelis et al. 2013). On the other hand, the contemporary ranges of both Poecilimon and Isophya largely overlap; yet, Isophya is not represented in the southern and southwestern part of the Aegean (most of mainland Greece, Crete and the majority of the Aegean islands), while Poecilimon occurs with a number of taxa all over the Aegean area. Thus, as a working hypothesis to be tested, we assume that Isophya represents the main northern and Poecilimon represents the main southern lineage of Barbitistini (see also Chobanov et al. 2017).

Tribus Barbitistini was claimed to be an impressive example of diversification within a limited spatial and temporal scale (Kaya et al. 2015; Grzywacz et al. 2018). The group
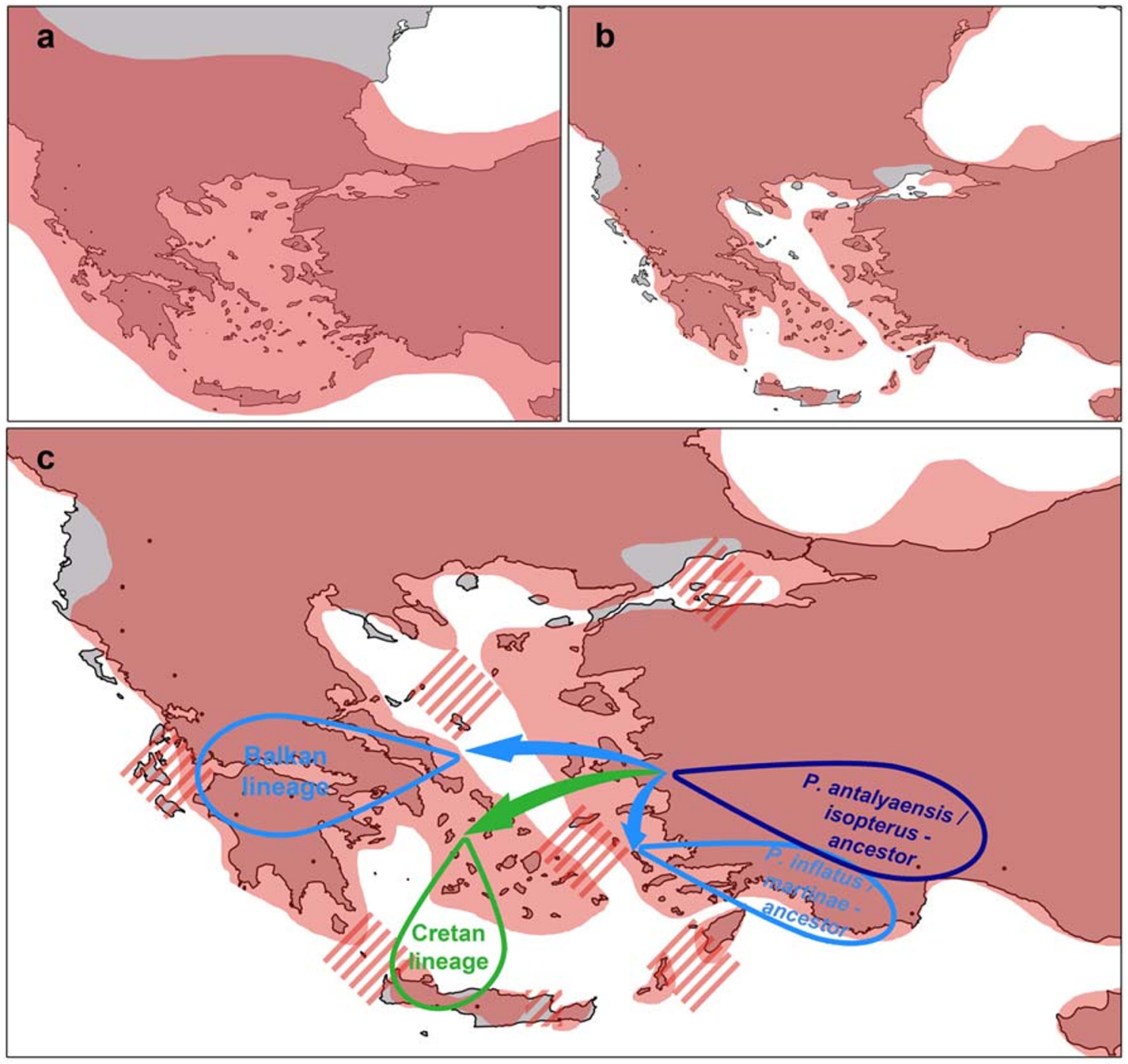

\section{Land}

Fig. 7 Land-sea configuration in the Aegean area in different periods of the Neogene based on reconstructions by Popov et al. (2004) (with details taken from Creutzburg 1963 and Dermitzakis 1990) with historical biogeography hypothesis for the Messinian. a Late Serravallian (12-11 Ma), a possible time for the origin and early divergence of Barbitistini; $\mathbf{b}$ late Tortonian (8.5-7 Ma), transgression of the Mid-Aegean area in Tortonian

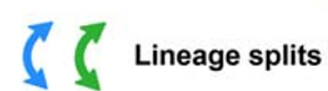

corresponds to TMRCA of Poecilimon and Isophya; and $\mathbf{c}$ late Messinian (6-5.6 Ma), the ancestor of Poecilimon jonicus group emerged on the Anatolian side of Aegean land in Messinian; the regression of Mid Aegean area during the MSC provided corridors for dispersal to Crete and the Balkans 
was thought to have recently evolved (since Miocene; Çıplak 2004; Chobanov et al. 2017) and is currently known with ca. 300 micropterous species concentrated in the Aegean and Pontic area (Cigliano et al. 2020). Chobanov et al. (2017) argued that genus Isophya evolved after the middle Miocene climatic transition from an "ephemeral" ancestor that developed fast within a short favorable season with appropriate humidity and temperatures. The loss of flight is beneficent to organisms that need to reduce energy costs in an ecologically harsh environment and is typical for insects of the dryer, cooler, and windier climates in comparison with tropical and temperate zones (e.g., Roff 1990; Grzywacz et al. 2018). Flightlessness on the other hand can promote diversification not only by contributing to isolation but also through acceleration of the mutation rates (Ikeda et al. 2012). Thus, a combination of geological (disintegration of the Aegean area) and climatic factors (the Middle Miocene Climatic Transition) may have initiated and accelerated the early evolution of Barbitistini.

\section{Evolution of Poecilimon jonicus group}

According to mitochondrial chronograms (Fig. 6a-c), $P$. jonicus group sensu lato shares a common ancestor $8-6$ Ma ago, a time well corresponding to the Messinian period of the Miocene. As the Anatolian clade ( $P$. antalyaensis + $P$. isopterus) constitutes the basal branch and the Cretan (P. cretensis) the subsequent one, Anatolian mainland seems to be the place of origin of the group ancestors. Hence, it can be assumed that desiccation in the Mediterranean during the Messinian salinity crisis (MSC) (5.96-5.33 Ma), especially in the Aegean area (e.g., Steininger and Rögl 1984; Dermitzakis 1990), provided distribution corridor for dispersal of an ancestral stock over the present distribution range of the group. However, the poorly resolved relationships between the Cretan, Balkan, and $P$. inflatus $+P$. martinae lineage suggest an early radiation within Anatolia or along the Aegean landmass connecting the Balkans and Anatolia during the MSC (Fig. 7c). The following post-Messinian transgression of the Mediterranean and Aegean area ca. 5.3-5.2 Ma (Jolivet et al. 2006) acted as a vicariant event resulting in four geographically isolated stocks-ancestral $P$. inflatus $+P$. martinae in Anatolia and $P$. cretensis in Crete, the Northern, and Southern Balkan group in the southern Balkan mainland and on the Peloponnesos, respectively (Fig. 8a). In that case, the expected phylogeny of the group will be [(P. antalyaensis + $P$. isopterus $)+(P$. cretensis $+(P$. inflatus $+P$. martinae $)+$ Northern Balkan clade + Southern Balkan clade)].

During Messinian, the level of the Mediterranean dropped after its isolation from the Atlantic. As a result of the MSC, the Aegean landmass was largely united again, and terrestrial migrations between the Balkan mainland and Crete were possible and documented (e.g., Dermitzakis 1990; Lymberakis et al. 2007). With the end of the Messinian 5.33 Ma ago and the Zanclean refill of the Mediterranean basin the Balkans, Anatolia and Crete were disconnected again ca. 5.2 Ma ago (Meulenkamp 1985; Dermitzakis 1990). We believe these two periods are of major importance for dispersal, early speciation, and subsequent vicariance leading to major lineage splits within the Poecilimon jonicus group (Figs. 7c, 8a). Within this time frame (5.8/5.6 to 5.2 Ma), the Cretan lineage was established and shortly after that the Balkan lineage splits into a Northern and a Southern group. Roughly at the same time, the $P$. inflatus branch (present P. inflatus $+P$. martinae) was established.

In Pliocene, the land-sea configuration further complicated with the development of many islands and peninsulas, as well as vast inland freshwater areas (marshes and lakes) (Popov et al. 2004) (Fig. 8a, b). The latter may have contributed to the basal lineage splits within the Northern Balkan group (P. werneri, P. jonicus superbus), Southern Balkan group ( $P$. erimanthos), and in the Anatolian group $(P$. antalyaensis and $P$. isopterus) due to vicariant events. Specifically, the lack of $P$. jonicus superbus in most of Puglia (southeastern corner of Italy) (Fig. 2), though this area represented an island at the time this taxon originated, may possibly be explained as a result of recent climatic factors.

Latest speciation events are dated to the Pleistocene, starting with the onset of the northern hemisphere glaciation (2.5-2.6 Ma ago), when climate cycles with alternating cooler drier and warmer more humid periods dominated the area. Those climate events have been suggested as triggers for recent lineage splits in other Barbitistini (Kaya et al. 2015; Chobanov et al. 2017). Pleistocene climate was dominated by two major climatic switches-first ca. 1.4 Ma, when 41Ka cold-warm cycles become constant, and second, $0.8 \mathrm{Ma}$, when 100-Ka cycles established (Lisiecki and Raymo 2007). Those periods of cooling and warming were connected not only with climate changes but also with sea level drops (glacials) and rises (interglacials). Thus, thermophilous animals dependent on modest humidity retreated to refuges and were isolated on islands during stadials (cold dry periods) and regained territories during interstadials (warm humid periods). Interesting correlation may be observed between the intraspecific divergence of the Cretan lineage ( $P$. cretensis) and the second Pleistocene climatic switch (Fig. 6b). Patterns of the evolutionary history of Cretan lineages based on early vicariance are documented in various groups (Parmakelis et al. 2005, 2006; Simaiakis and Mylonas 2008). Populations on the island were completely isolated after the end of the Messinian. Yet, the current appearance of Crete as a united landmass was established only recently, while many smaller island configurations existed during the Pliocene (Creutzburg 1963; Dermitzakis 1990; Douris et al. 1998; Welter-Schultes 2000) (Fig. 8a, b). Relatively high genetic distances between sampled populations of $P$. cretensis could be a reflection of 


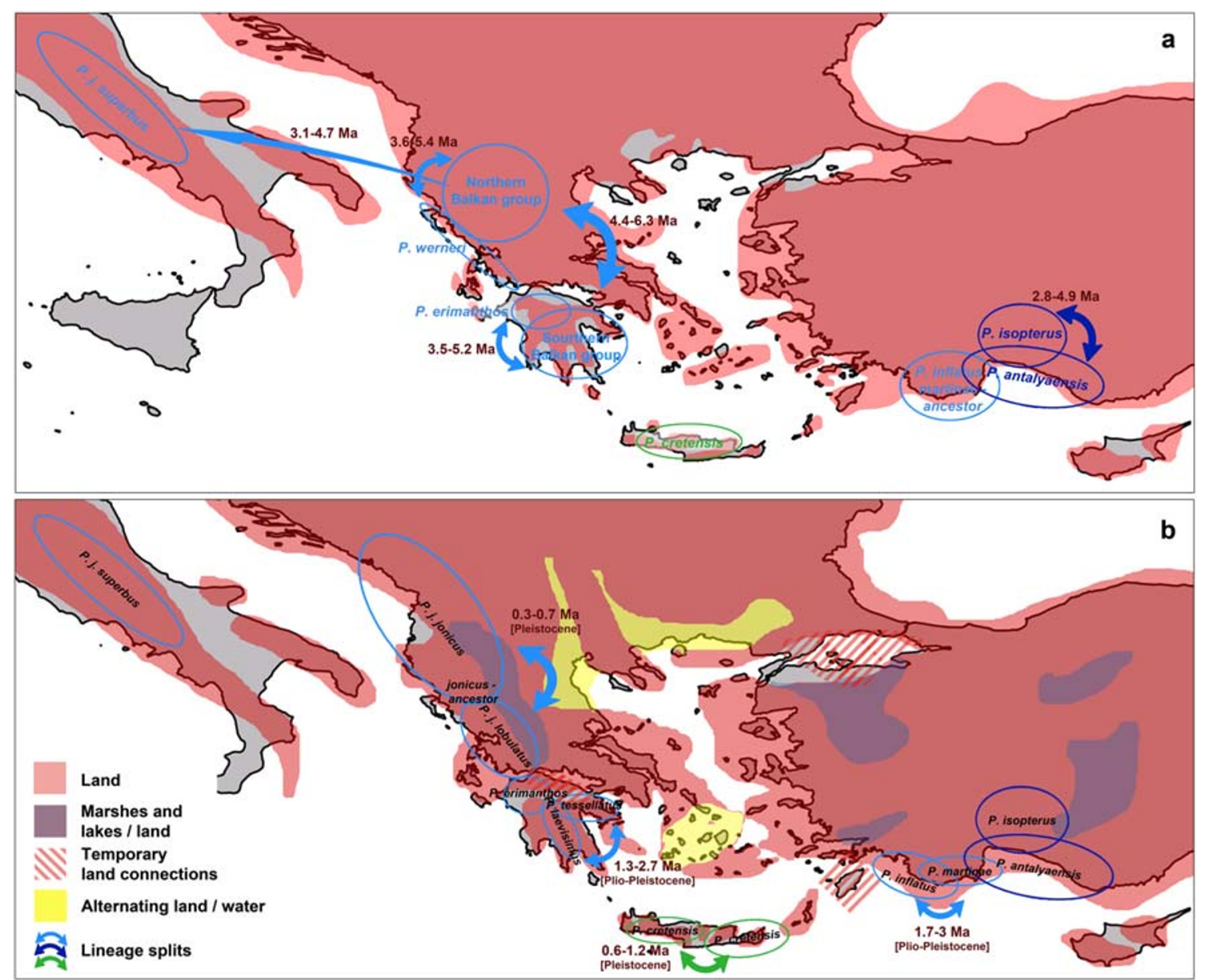

Fig. 8 Land-sea configuration in the Aegean area in different periods of the Neogene based on reconstructions by Popov et al. (2004) (with details taken from Creutzburg 1963 and Dermitzakis 1990) with historical biogeography hypotheses for the evolution of the P. jonicus group. a Midlate Pliocene (ca. 3.5 Ma), transgression of the Aegean area at the end of Messinian/beginning of Pliocene led to vicariant speciations in Anatolia,
Crete, and the Balkans and b late Pliocene-Mid Pleistocene (ca. 3.4-0.4 $\mathrm{Ma}$ ), fluctuating levels of the Mediterranean Sea, small-scale geotectonic events and climatic cycles leading to frequent transformations in the landsea configuration contributed to the recent history of Poecilimon jonicus group vicariant events during the Pleistocene as a result of isolation of the easternmost Cretan territory by lakes/brackish waters around that time.

\section{Implications for the systematics of Poecilimon jonicus group}

Clear implications about the systematics of $P$. jonicus group sensu lato may be outlined from the present study. Both nuclear and mitochondrial DNA sequences support a clear monophyletic outline of the group including the present $P$. jonicus and $P$. inflatus species groups and excluding $P$. bilgeri. Although the group is monophyletic, its basal internal phylogeny is not doubtlessly resolved. Though both mitochondrial trees agree for the ancestral position of the Anatolian P. antalyaensis (+ $P$. isopterus), the Cretan, Northern Balkan, Southern Balkan, and the Anatolian $P$. inflatus $+P$. martinae clades have unresolved relationships. The phylogenetic position of $P$. inflatus is especially intriguing, as it appears as an internal branch of the Balkan lineages with very high support in the ND2 + COI phylogeny, at the same time occurring at the opposite side of the Aegean Sea. Yet, based on the long history of the discussed lineages and contradictions in the trees, independent evolution of each genome is possible (Bernardo et al. 2019). The instability at the base of the $P$. jonicus group tree may express a real situation. If a contemporary split of the Balkan, Cretan, and Anatolian lineages by the end of Messinian is assumed, then a basal polytomy or basal instability will be expected.

All taxa currently recognized in the group seem to represent distinct phylogenetic units, and the position of certain lineages allows for accepting a higher number of species. For instance, $P$. tessellatus groups with $P$. laevissimus and is clearly distinct from $P$. jonicus, with which it was recently united; yet, $P$. jonicus jonicus and $P$. $j$. lobulatus seem representing distinct units with a subspecies rank. Poecilimon jonicus superbus, occurring in the Apennines, 
shows large genetic distances from $P$.j.jonicus and $P$. jonicus lobulatus, exceeding those between $P$. inflatus and $P$. martinae and comparable with those between the well morpho-acoustically distinguished $P$. antalyaensis and $P$. isopterus. The divergence between haplotypes of $P$. cretensis is prominent, and its genetic subdivision extends those of $P$. jonicus and $P$. antalyaensis (for $P$. a. antalyaensis and $P$. a. myrae). On the other hand, genetic distances between subspecies of $P$. inflatus and $P$. antalyaensis (subspecies of $P$. martinae not included in the study) (see Kaya et al. 2018) support their status.

Actual taxonomic changes arising from our results are the following. Poecilimon jonicus tessellatus was initially described as a distinct species, and later, it was synonymized with $P$. jonicus and obtained subspecies status (Heller 1988). Although similarities with $P$. jonicus are obvious, the molecular phylogeny of the group points out that $P . j$. tessellatus is part of the Southern Balkan group and has not common evolutionary history with $P$. jonicus being relative to $P$. laevissimus. Divergence between $P$. j. jonicus and $P$. j. tessellatus is also observed in the distinct song patterns (compare Fig. 9). While our data suggests that $P . j$. tessellatus characterizes with a stable complex song pattern with an isolated short main syllable and two complex after parts (Fig. 9a) (compare the stridulatory movement by Heller 1988 - Abb. $36 \mathrm{H}$ ), possibly rarely involving only the main part (Heller 1988 - Abb. 36 G), own and published data for
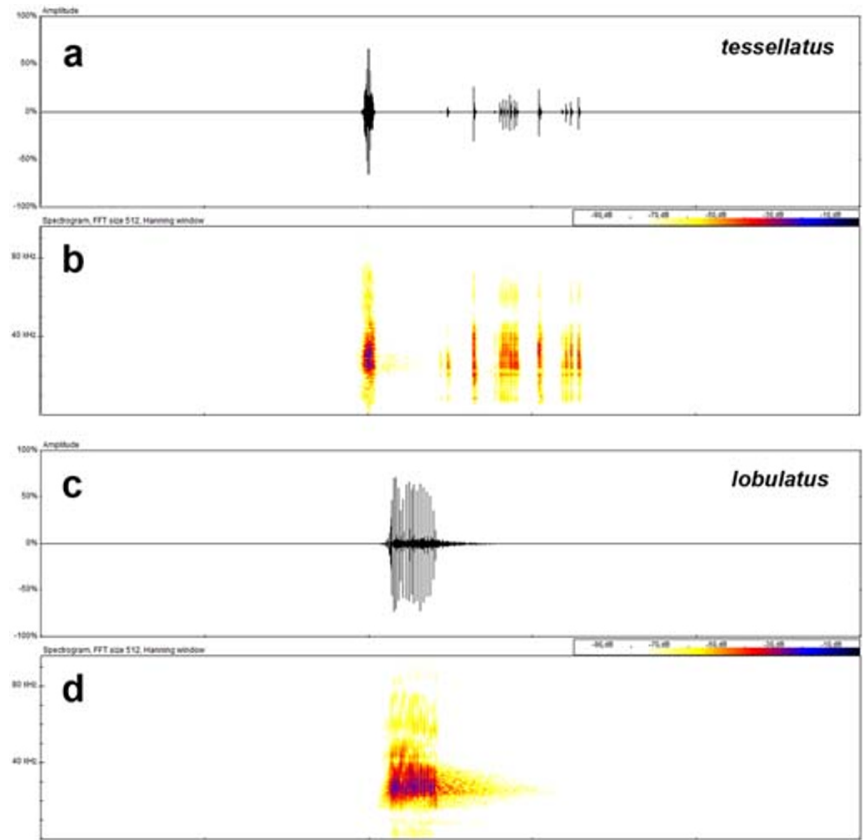

Fig. 9 Examples of the male calling song presented in a time frame of $500 \mathrm{~ms}$ with oscillograms $(\mathbf{a}, \mathbf{c}, \mathbf{e}, \mathbf{f}, \mathbf{g}, \mathbf{h})$ and spectrograms $(\mathbf{b}, \mathbf{d})$ of taxa currently considered subspecies of Poecilimon jonicus. a $P$. j. tessellatus, Greece, Peloponnesos, Kallithea, $22.4^{\circ} \mathrm{C}$, daily recording, own data; b same; c P. j. lobulatus, mainland Greece, Amphilochia, $21^{\circ} \mathrm{C}$, daily recording, own data; d same; e P. j. jonicus, Albania, Kolonje district, other subspecies of $P$. jonicus suggest mostly a simple song pattern with a long main syllable (compare the stridulatory movement by Heller 1988 - Abb. 36 E, F). Yet, single after parts are present in some recordings of $P$. jonicus (Fig. $9 \mathrm{e}, \mathrm{g})$. On the other hand, though the song of $P . j$. superbus (also described as a distinct species) is almost identical to that of $P . j$. jonicus, we revealed large genetic distances between them, suggesting 3.1 to $4.7 \mathrm{Myr}$ of isolation (Figs. $6 c, 8 a)$. Considering the fact that closely related allopatric bush crickets usually retain a conservative song pattern (Heller 2006) and that the genetic differentiation of $P . j$. superbus is comparable with that of well-distinguished sympatric taxa within the group, we may conclude for its species status.

Concluding from the above discussion, we propose the following systematic and nomenclatural changes. Poecilimon bilgeri, currently related to P. inflatus (Kaya et al. 2018), does not belong to the Poecilimon jonicus group sensu lato and is relative to Poecilimon pergamicus (this study and own unpublished data). Poecilimon jonicus group represents a monophyletic lineage, whose basal clades diversified within a short time frame and thus (at the present state of knowledge) cannot be divided to less than four or five taxonomic complexes; therefore, the existence of Poecilimon inflatus group (Kaya et al. 2018) is not justified. Hence, the current assemblage of the Poecilimon jonicus group (stat. rev.) is as follows (in alphabetical order):
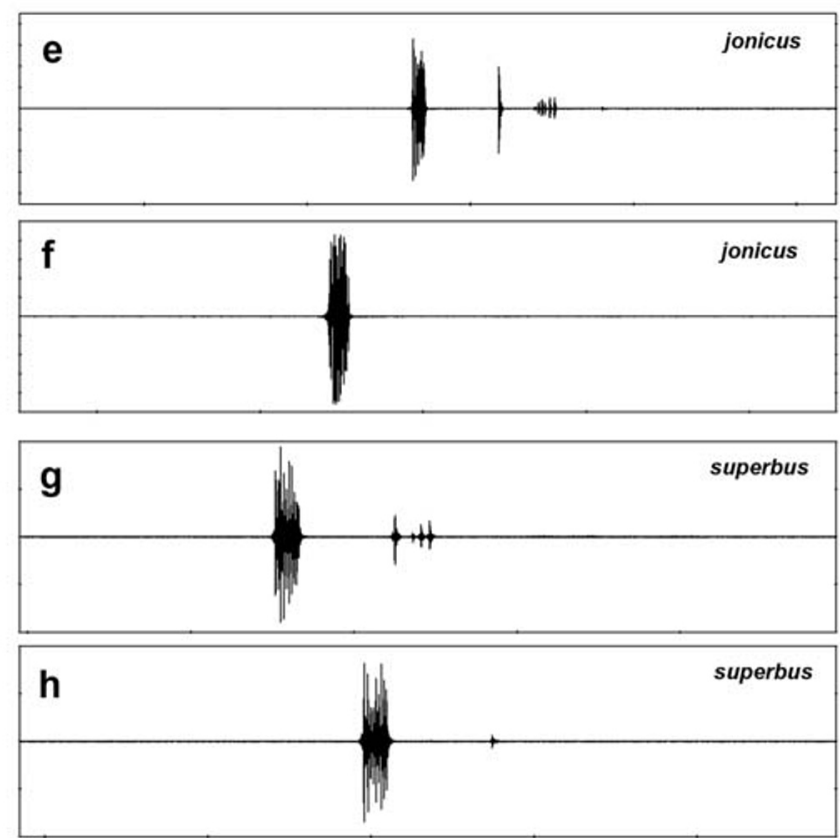

Qafa e Qarrit pass, $1.5 \mathrm{~km}$ W of Pepellash, $1200 \mathrm{~m}$ a.s.1, lab recording, $30^{\circ} \mathrm{C}, \mathrm{ZOOM}-\mathrm{H} 4$ digital recorder, sample rate $96 \mathrm{kHz}$, G. Puskas, source: OSF online; f $P$. j. jonicus, Albania, S of Vlorë, $\mathrm{N}$ of Qeparo vill., ca. $25^{\circ} \mathrm{C}$, daily recording, own data; g $P . j$. superbus, Italy, Liguria, Orsomarso, Valle Fiume Argentino, $25^{\circ} \mathrm{C}$, source: Massa et al. 2012; and $\mathbf{h}$ same, different part of the recording 
Poecilimon antalyaensis anemurium Kaya, Chobanov \& Çiplak, 2018

P. antalyaensis antalyaensis (Karabag, 1975)

P. antalyaensis myrae Chobanov \& Heller, 2018

$P$. cretensis Werner, 1903

P. erimanthos Willemse \& Heller, 1992

$P$. inflatus inflatus Brunner von Wattenwyl, 1891

P. inflatus lyciae Kaya \& Çıplak, 2018

P. isopterus Kaya \& Chobanov, 2018

P. jonicus jonicus (Fieber, 1853)

P. jonicus lobulatus Willemse, 1982

P. laevissimus (Fischer, 1853)

$P$. martinae martinae Heller, 2004

P. martinae tlos Heller, 2004

P. superbus (Fischer, 1853), stat. rev.

P. tessellatus (Fischer, 1853), stat. rev.

P. werneri Ramme, 1933

\section{Conclusion}

The dynamic geological history of the Aegean contributed to complex evolutionary patterns in terrestrial animals. The flightlessness in bush crickets was an additional trigger to isolation and thus speciation. Specializing in allopatry, the lineages did not require prompt changes in morphology, and sexual selection could have induced slow change. Thus, comparatively small to the eye morphological and behavioral differences corresponded to long-term speciation in isolation. Our molecular phylogenetic analyses provided a different viewpoint to the problem and suggested robust phylogeny of the Poecilimon jonicus group in a broad sense in parallel revealing a strong link between its evolution and the geomorphological history of the Aegean.

Acknowledgments We thank two anonymous reviewers for their valuable comments allowing significant improvement of this paper. For the help with field studies in Greece we sincerely thank Vassiliki Kati and the Greek authorities (material collected with permission 154812/951 from 6.6.2017).

Funding This study was supported by the National Science Fund (MES) of Bulgaria - project DN11/14-18.12.2017 to Dragan Chobanov and by the Program for Supporting Young Scientists of the Bulgarian Academy of Sciences - Project 17-86/27.08.2017 to Simeon Borissov. The material was collected with the support by The Teodore J. Cohn Research Fund (OSF), Deutsche Gesselschaft für Orthopterologie (grants to Simeon Borissov), and a joint project 'Phylogenetic relationships in the group Barbitistini (Orthoptera, Tettigoniidae, Phaneropterinae) based on genetic studies' of D. Chobanov and B. Çıplak. The Scientific and Technological Research Council of Turkey (TÜBITAK) (postdoctoral research grant to Dragan Chobanov) supported the acquisition of sequences from Anatolian specimens.

Data availability The datasets generated and/or analyzed during the current study will be freely available after July 1, 2020. Edited and aligned sequences from this study are referred to GenBank (https://www.ncbi. nlm.nih.gov/genbank/) accession numbers given in Supplementary material A. Phylogenetic and timetrees will be available from DRYAD (https://datadryad.org/stash). All published and unpublished data are also available from the corresponding author on reasonable request.

Open Access This article is licensed under a Creative Commons Attribution 4.0 International License, which permits use, sharing, adaptation, distribution and reproduction in any medium or format, as long as you give appropriate credit to the original author(s) and the source, provide a link to the Creative Commons licence, and indicate if changes were made. The images or other third party material in this article are included in the article's Creative Commons licence, unless indicated otherwise in a credit line to the material. If material is not included in the article's Creative Commons licence and your intended use is not permitted by statutory regulation or exceeds the permitted use, you will need to obtain permission directly from the copyright holder. To view a copy of this licence, visit http://creativecommons.org/licenses/by/4.0/.

\section{References}

Allegrucci, G., Ketmaier, V., Di Russo, C., Rampini, M., Sbordoni, V., \& Cobolli, M. (2017). Molecular phylogeography of Troglophilus cave crickets (Orthoptera, Rhaphidophoridae): A combination of vicariance and dispersal drove diversification in the East Mediterranean region. Journal of Zoological Systematics and Evolutionary Research, 55(4), 310-325. https://doi.org/10.1111/ jzs. 12172.

Anastasakis, G., Piper, D. J. W., Dermitzakis, M. D., \& Karakitsios, V. (2006). Upper Cenozoic stratigraphy and paleogeographic evolution of Myrtoon and adjacent basins, Aegean Sea, Greece. Marine and Petroleum Geology, 23, 353-369.

Beerli, P., Hotz, H., \& Uzzell, T. (1996). Geologically dated sea barriers calibrate a protein clock for Aegean water frogs. Evolution, 50(4), 1676-1687.

Bernardo, P. H., Sánchez-Ramírez, S., Sánchez-Pacheco, S. J., ÁlvarezCastañeda, S. T., Aguilera-Miller, E. F., Mendez-de la Cruz, F. R., \& Murphy, R. W. (2019). Extreme mito-nuclear discordance in a peninsular lizard: the role of drift, selection, and climate. Heredity, 123(3), 359-370. https://doi.org/10.1038/s41437-019-0204-4.

Boc, A., Diallo, A. B., \& Makarenkov, V. (2012). T-REX: A web server for inferring, validating and visualizing phylogenetic trees and networks. Nucleic Acids Research, 40(W1), W573-W579.

Bouckaert, R., Vaughan, T. G., Barido-Sottani, J., Duchêne, S., Fourment, M., Gavryushkina, A., et al. (2019). BEAST 2.5: An advanced software platform for Bayesian evolutionary analysis. PLoS Computational Biology, 15(4), e1006650.

Brower, A. V. Z. (1994). Rapid morphological radiation and convergence among races of the butterfly Heliconius erato inferred from patterns of mitochondrial DNA Evolution. Proceedings of the National Academy of Sciences of the United States of America, 91, 64916495.

Chobanov, D. P., \& Heller, K.-G. (2010). Revision of the Poecilimon ornatus group (Orthoptera: Phaneropteridae) with particular reference to the taxa in Bulgaria and Macedonia. European Journal of Entomology, 107, 647-672.

Chobanov, D. P., Kaya, S., Grzywacz, B., Warchałowska-Śliwa, E., \& Çıplak, B. (2017). The Anatolio-Balkan phylogeographic fault: A snapshot from the genus Isophya (Orthoptera, Tettigoniidae). Zoologica Scripta, 46(2), 165-179. https://doi.org/10.1111/zsc. 12194.

Cigliano, M.M., Braun, H., Eades, D.C., \& Otte, D. (2020). Orthoptera species file. Version 5.0/5.0. http://Orthoptera.SpeciesFile.org. Accessed May 2020. 
Çıplak, B. (2004). Biogeography of Anatolia: The marker group Orthoptera. Memorie della Società Entomologica Italiana, 82, 357-372.

Çıplak, B., Heller, K.-G., \& Willemse, F. (2010). Phylogeny and biogeography Eupholidoptera Maran (Orthoptera, Tettigoniidae): Morphological speciation in correlation with the geographical evolution of the eastern Mediterranean. Systematic Entomology, 35, $722-738$.

Creutzburg, N. (1963). Palaeogeographic evolution of Crete from Miocene till our days. Cretan Annals, 15/16, 336-342.

Darriba, D., Taboada, G. L., Doallo, R., \& Posada, D. (2012). jModelTest 2: More models, new heuristics and parallel computing. Nature Methods, 9(8), 772.

Dermitzakis, M. D. (1990). The colonization of Aegean islands in relation with the paleogeographic evolution. Biologia Gallo-Hellenica, 14, 99-121.

Dermitzakis, D. M., \& Papanikolaou, D. J. (1981). Paleogeography and geodynamics of the Aegean region during the Neogene. Annales Géologiques des Pays Helléniques, 30, 245-289.

Douris, V., Cameron, R. A. D., Rodakis, G. C., \& Lekanidou, R. (1998). Mitochondrial phylogeography of the land snail Albinaria in Crete: Long-term geological and short-term vicariance effects. Evolution, $52,116-125$

Douris, V., Giokas, S., Thomaz, D., Lecanidou, R., \& Rodakis, G. C. (2007). Inference of evolutionary patterns of the land snail Albinaria in the Aegean archipelago: Is vicariance enough? Molecular Phylogenetics and Evolution, 44, 1224-1236. https://doi.org/10. 1016/j.ympev.2007.01.004.

Drummond, A. J., Ho, S. Y., Phillips, M. J., \& Rambaut, A. (2006). Relaxed phylogenetics and dating with confidence. PLoS Biol, 4(5), e88.

Gantenbein, B., \& Keightley, P. D. (2004). Rates of molecular evolution in nuclear genes of east Mediterranean scorpions. Evolution, 58, 2486-2497.

Grzywacz, B., Lehmann, A. W., Chobanov, D. P., \& Lehmann, G. U. C. (2018). Multiple origin of flightlessness in Phaneropterinae bushcrickets and redefinition of the tribus Odonturini (Orthoptera: Tettigonioidea: Phaneropteridae). Organisms, Diversity and Evolution, 18, 327-339. https://doi.org/10.1007/s13127-018-0370$\mathrm{x}$.

Heller, K.-G. (1984). Zur Bioakustik und Phylogenie der Gattung Poecilimon Orthoptera, Tettigoniidae, Phaneropterinae. Zoologische Jahrbucher: Abteilung für Systematik, 111, 69-117.

Heller, K.-G. (1988). Bioakustik der Europäischen Laubheuschrecken. Weikersheim: J. Margraf.

Heller, K.-G. (2004). Poecilimon martinae n. sp. and P. inflatus Brunner von Wattenwyl, 1891 (Orthoptera, Tettigonioidea, Phaneropteridae), two bush-cricket species endemic to southwest Anatolia: Morphology, bioacoustics and systematics. Articulata, 19, 1-17.

Heller, K.-G. (2006). Song evolution and speciation in bushcrickets. In S. Drosopoulos \& M. F. Claridge (Eds.), Insect sounds and communication, physiology, behaviour, ecology and evolution (pp. 207219). Boca Raton: CRC Press.

Heller, K.-G., Willemse, L., Baudewijn, O., Volleth, M., Feist, R., \& Reinhold, K. (2011). Bioacoustics and systematics of the Poecilimon hamatus Group (Tettigonioidea: Phaneropteridae: Poecilimon: Hamatopoecilimon n. subg.). Journal of Orthoptera Research, 20, 81-95. https://doi.org/10.1665/034.020.0108.

Hochkirch, A., Massa, B., Heller, K.-G., Willemse, L. P. M., Rutschmann, F., Chobanov, D. P., Kleukers, R., Kristin, A., Presa, J. J., \& Szovenyi, G. (2016). Poecilimon laevissimus. The IUCN Red List of Threatened Species, 2016, e.T68455994A74528394. https:// doi.org/10.2305/IUCN.UK.2016-3.RLTS.T68455994A74528394. en.
Ikeda, H., Nishikawa, M., \& Sota, T. (2012). Loss of flight promotes beetle diversification. Nature Communications, 3, 648.

Jolivet, L., Augier, R., Robin, C., Suc, J. P., \& Rouchy, J. M. (2006). Lithospheric-scale geodynamic context of the Messinian salinity crisis. Sedimentary Geology, 188, 9-33.

Kasapidis, P., Magoulas, A., Mylonas, M., \& Zouros, E. (2005). The phylogeography of the gecko Cyrtopodion kotschyi (Reptilia: Gekkonidae) in the Aegean archipelago. Molecular Phylogenetics and Evolution, 35, 612-623.

Kaya, S., Boztepe, Z., \& Çıplak, B. (2015). Phylogeography of the Poecilimon luschani species group (Orthoptera, Tettigoniidae): A radiation strictly correlated with climatic transitions in the Pleistocene. Zoological Journal of the Linnean Society, 173, 1-21.

Kaya, S., \& Çiplak, B. (2016). Budding speciation via peripheral isolation: The Psorodonotus venosus (Orthoptera, Tettigoniidae) species group example. Zoologica Scripta, 45, 521-537. https://doi.org/10. 1111/zsc. 12174

Kaya, S., \& Çıplak, B. (2017). Phylogeography of Psorodonotus caucasicus group: Independent double invasion of Balkans from Transcaucasia. Systematic Entomology, 42(1), 118-133.

Kaya, S., Chobanov, D., Heller, K.-G., Yahyaoglu, Ö., Uluar, O., \& Çıplak, B. (2018). Review of Poecilimon species with inflated pronotum: Description of four new taxa within an acoustically diverse group. Zootaxa, 4462(4), 451-482.

Korkmaz, E. M., Lunt, D. H., Çıplak, B., Değerli, N., \& Başıüyük, H. H. (2014). The contribution of Anatolia to European phylogeography: The centre of origin for the meadow grasshopper Chorthippus parallelus. Journal of Biogeography, 41, 1793-1805.

Kumar, S., Stecher, G., Li, M., Knyaz, C., \& Tamura, K. (2018). MEGA $\mathrm{X}$ : Molecular evolutionary genetics analysis across computing platforms. Molecular Biology and Evolution, 35, 1547-1549.

La Greca, M. (1999). Il contributo degli Ortotteri (Insecta) alla conoscenza della biogeografia dell' Anatolia: la componente gondwaniana. Biogeographia, 20, 179-200.

Lanfear, R., Frandsen, P. B., Wright, A. M., Senfeld, T., \& Calcott, B. (2016). PartitionFinder 2: new methods for selecting partitioned models of evolution for molecular and morphological phylogenetic analyses. Molecular biology and evolution, 34(3), 772-773.

Librado, P., \& Rozas, J. (2009). DnaSP v5: A software for comprehensive analysis of DNA polymorphism data. Bioinformatics, 25, 14511452.

Lisiecki, L. E., \& Raymo, M. E. (2007). Plio-Pleistocene climate evolution: Trends and transitions in glacial cycle dynamics. Quaternary Science Reviews, 26, 56-59.

Loget, N., Davy, P., \& Van Den Driessche, J. (2006). Mesoscale fluvial erosion parameters deduced from modeling the Mediterranean sea level drop during the Messinian (late Miocene). Journal of Geophysical Research, 111, F03005. https://doi.org/10.1029/ $2005 J F 000387$.

Lymberakis, P., Poulakakis, N., Manthalou, G., Tsigenopoulos, C. S., Magoulas, A., \& Mylonas, M. (2007). Mitochondrial phylogeography of Rana (Pelophylax) populations in the Eastern Mediterranean region. Molecular Phylogenetics and Evolution, 44, $115-125$.

Massa, B., Fontana, P., Buzetti, F. M., Kleukers, R., \& Odé, B. (2012). Orthoptera. Fauna d'Italia, vol., 48.

Meulenkamp, J. E. (1977). The Aegean and the Messinian salinity crisis. Proc. 6th Coll. Geol. Aegean Region, 3, 1253-1263.

Meulenkamp, J. E. (1985). Aspects of the late Cenozoic evolution of the Aegean region. In D. J. Stanley \& F. C. Wezel (Eds.), Geological Evolution of the Mediterranean Basin (pp. 307-321). New York: Springer.

Miller, M. A., Pfeiffer, W., \& Schwartz, T. (2010, November). Creating the CIPRES Science Gateway for inference of large phylogenetic trees. In 2010 gateway computing environments workshop (GCE) (pp. 1-8). IEEE. 
Papadopoulou, A., Anastasiou, I., \& Vogler, A. P. (2010). Revisiting the insect molecular clock: The Mid-Aegean Trench calibration. Molecular Biology and Evolution, 27, 1659-1672.

Parmakelis, A., Kotsakiozi, P., Stathi, I., Poulikarakou, S., \& Fet, V. (2013). Hidden diversity of Euscorpius (Scorpiones: Euscorpiidae) in Greece revealed by multilocus species-delimitation approaches. Biological Journal of the Linnean Society, 110, 728-748.

Parmakelis, A., Pfenninger, I., Spanos, L., Papagiannakis, G., Louis, C., \& Mylonas, M. (2005). Inference of a radiation in Mastus (Gastropoda, Pulmonata, Enidae) on the island of Crete. Evolution, 59, 991-1005.

Parmakelis, A., Stathi, I., Chatzaki, M., Simaiakis, S., Spanos, L., Louis, C., \& Mylonas, M. (2006). Evolution of Mesobuthus gibbosus (Brulle, 1832) (Scorpiones: Buthidae) in the northeastern Mediterranean region. Molecular Ecology, 15(10), 2883-2894.

Percy, D. M., Page, R. D. M., \& Cronk, Q. C. B. (2004). Plant-insect interactions: double-dating associated insect and plant lineages reveals asynchronous radiations. Systematic Biology, 53(1), 120-127.

Popov, S. V., Antipov, M. P., Zastrozhnov, A. S., Kurina, E. E., \& Pinchuk, T. N. (2010). Sea-level fluctuations on the Northern Shelf of the Eastern Paratethys in the Oligocene-Neogene. Stratigraphy and Geological Correlation, 18(2), 200-224.

Popov, S. V., Rögl, F., Rozanov, A. Y., Steininger, F. F., Shcherba, I. G., \& Kovac, M. (2004). Lithological-paleogeographic maps of Paratethys 10 maps late Eocene to Pliocene, 46 pages, maps 1-10 (annex).

Poulakakis, N., Lymberakis, P., Tsigenopoulos, C. S., Magoulas, A., \& Mylonas, M. (2005a). Phylogenetic relationships and evolutionary history of snake-eyed skink Ablepharus kitaibelii (Sauria: Scincidae). Molecular Phylogenetics and Evolution, 34, 245-256.

Poulakakis, N., Lymberakis, P., Valakos, E., Pafilis, P., Zouros, E., \& Mylonas, M. (2005b). Phylogeography of Balkan wall lizard (Podarcis taurica) and its relatives inferred from mitochondrial DNA sequences. Molecular Ecology, 14, 2433-2443.

Poulakakis, N., Paschalia, K., Lymberakis, P., Trichas, A., Vardinoyannis, K., Sfenthourakis, S., \& Mylonas, M. (2014). A review of phylogeographic analyses of animal taxa from the Aegean and surrounding regions. Journal of Zoological Systematics and Evolutionary Research, 53(1), 18-32. https://doi. org/10.1111/jzs.12071.

Rambaut, A., \& Drummond, A. J. (2002-2019). TreeAnnotator. Ver.2.5.2 [Computer software and manual]. Available via http:// beast.bio.ed.ac.uk/treeannotator.

Rambaut, A., Drummond, A. J., Xie, D., Baele, G., \& Suchard, M. A. (2018). Posterior summarisation in Bayesian phylogenetics using Tracer 1.7. Systematic Biology, 67(5), 901. https://doi.org/10.1093/ sysbio/syy032.

Roff, D. A. (1990). The evolution of flightlessness in insects. Ecological Monographs, 60, 389-421.

Ronquist, F., \& Huelsenbeck, J. P. (2003). MrBayes version 3.0: Bayesian phylogenetic inference under mixed models. Bioinformatics, 19(12), 1572-1574.

Ronquist, F., Huelsenbeck, J. P., \& van der Mark, P. (2005). MrBayes 3.1 manual. Draft 5/26/2005. Available at http://mrbayes.csit.fsu.edu/ manual.php.

Sevgili, H., Șìrİn, D., Heller, K. G., \& Lemonnier-Darcemont, M. (2018). Review of the Poecilimon (Poecilimon) zonatus species group and description of new species from Turkey with data on bioacoustics and morphology (Orthoptera: Phaneropterinae). Zootaxa, 4417(1), $1-62$.

Shapiro, L. H., Strazanac, J. S., \& Roderick, G. K. (2006). Molecular phylogeny of Banza (Orthoptera: Tettigoniidae), the endemic katydids of the Hawaiian archipelago. Molecular Phylogenetics and Evolution, 41(1), 53-63.

Shaw, K. L., \& Gillespie, R. G. (2016). Comparative phylogeography of oceanic archipelagos: Hotspots for inferences of evolutionary process. Proceedings of the National Academy of Sciences, 113(29), 7986-7993.

Simaiakis, S., \& Mylonas, M. (2008). The Scolopendra species (Chilopoda: Scolopendromorpha: Scolopendridae) of Greece (EMediterranean): A theoretical approach on the effect of geography and palaeogeography on their distribution. Zootaxa, 3, 39-53. https://doi.org/10.5281/zenodo.182561.

Simon, S., Buckley, T. R., Frati, F., Stewart, J. B., \& Beckenbach, A. T. (2006). Incorporating molecular evolution into phylogenetic analysis, and a new compilation of conserved polymerase chain reaction primers for animal mitochondrial DNA. Annual Review of Ecology, Evolution, and Systematics, 37, 545-579.

Simon, C., Frati, F., Beckenbach, A., Crespi, B., Liu, H., \& Flook, P. (1994). Evolution, weighting, and phylogenetic utility of mitochondrial gene sequences and a compilation of conserved polymerase chain reaction primers. Annals of the Entomological Society of America, 87(6), 651-701.

Stamatakis, A. (2006). RAxML-VI-HPC: Maximum likelihood-based phylogenetic analyses with thousands of taxa and mixed models. Bioinformatics, 22(21), 2688-2690.

Steininger, F., \& Rögl, F. (1984). Palaeogeography and palinspastic reconstruction of the Neogene of the Mediterranean Paratethys. The Geological Evolution of the Eastern Mediterranean. Geological Society of London, Special Publication, 17, 659-668. https://doi. org/10.1144/GSL.SP.1984.017.01.52.

Tamura, K., Battistuzzi, F. U., Billing-Ross, P., Murillo, O., Filipski, A., \& Kumar, S. (2012). Estimating divergence times in large molecular phylogenies. Proceedings of the National Academy of Sciences, 109, 19333-19338.

Tamura, K., \& Nei, M. (1993). Estimation of the number of nucleotide substitutions in the control region of mitochondrial DNA in humans and chimpanzees. Molecular Biology and Evolution, 10, 512-526.

Tamura, K., Qiqing, T., \& Kumar, S. (2018). Theoretical foundation of the RelTime method for estimating divergence times from variable evolutionary rates. Molecular Biology and Evolution, 35, 17701782

Triantis, K. A., \& Mylonas, M. (2009). Greek islands, Biology. In R. G. Gillespie \& D. A. Clague (Eds.), Encyclopedia of islands (pp. 388392). Berkeley: University of California Press.

Ullrich, B., Reinhold, K., Niehuis, O., \& Misof, B. (2010). Secondary structure and phylogenetic analysis of the internal transcribed spacers 1 and 2 of bush crickets (Orthoptera: Tettigoniidae: Barbitistini). Journal of Zoological Systematics and Evolutionary Research, 48, 219-228.

Vogler, A. P., \& Timmermans, M. J. T. N. (2012). Speciation: Don't fly and diversify? Current Biology, 22(8), 284-286.

Weekers, P. H. H., De Jonckheere, J. F., \& Dumont, H. J. (2001). Phylogenetic relationships inferred from ribosomal ITS sequences and biogeographic patterns in representatives of the genus Calopteryx (Insecta:Odonata) of the West Mediterranean and adjacent West European zone. Molecular Phylogenetics and Evolution, 20(1), 89-99.

Welter-Schultes, F. W. (2000). Geographic forms of the land snail Albinaria hippolyti as potential end members of phylogenetic lineages (Gastropoda: Clausiliidae). Biologia Gallo-hellenica, 26(1), $41-68$.

Xia, X. (2018). DAMBE7: New and improved tools for data analysis in molecular biology and evolution. Molecular Biology and Evolution, $35,1550-1552$.

Xia, X. H., Xie, Z., Salemi, M., Chen, L., \& Wang, Y. (2003). An index of substitution saturation and its application. Molecular Phylogenetics and Evolution, 26, 1-7.

Publisher's note Springer Nature remains neutral with regard to jurisdictional claims in published maps and institutional affiliations. 